\title{
Spectroscopic evidence for NAT, STS, and ice in MIPAS infrared limb emission measurements of polar stratospheric clouds
}

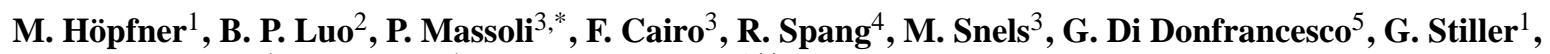 \\ T. von Clarmann ${ }^{1}$, H. Fischer ${ }^{1}$, and U. Biermann ${ }^{6, * *}$ \\ ${ }^{1}$ Forschungszentrum Karlsruhe, Institut für Meteorologie und Klimaforschung, Karlsruhe, Germany \\ ${ }^{2}$ Institut für Atmosphäre und Klima, ETH-Hönggerberg, Zürich, Switzerland \\ ${ }^{3}$ Consiglio Nazionale delle Ricerche, Istituto di Scienze dell'Atmosfera e del Clima, Rome, Italy \\ ${ }^{4}$ Forschungszentrum Jülich, Institut für Chemie und Dynamik der Geosphäre, Jülich, Germany \\ ${ }^{5}$ Ente per le Nuove tecnologie, l'Energie e l'Ambiente, Rome, Italy \\ ${ }^{6}$ Max-Planck-Institut für Chemie, Abteilung Atmosphärenchemie, Mainz, Germany \\ *now at: University of Colorado, Cooperative Institute for Research in the Environmental Sciences, Boulder, CO, USA \\ *** now at: Referat für Umwelt- und Energiepolitik des SPD-Parteivorstandes, Berlin, Germany
}

Received: 19 July 2005 - Published in Atmos. Chem. Phys. Discuss.: 26 October 2005

Revised: 3 February 2006 - Accepted: 21 February 2006 - Published: 20 April 2006

\begin{abstract}
We have analyzed mid-infrared limb-emission measurements of polar stratospheric clouds (PSCs) by the Michelson Interferometer for Passive Atmospheric Sounding (MIPAS) during the Antarctic winter 2003 with respect to PSC composition. Coincident Lidar observations from McMurdo were used for comparison with PSC types $1 \mathrm{a}, 1 \mathrm{~b}$ and 2. Application of new refractive index data of $\beta$-NAT have allowed to accurately simulate the prominent spectral band at $820 \mathrm{~cm}^{-1}$ observed by MIPAS at the location where the Lidar instrument observed type 1a PSCs. Broadband spectral fits covering the range from 780 to $960 \mathrm{~cm}^{-1}$ and from 1220 to $1490 \mathrm{~cm}^{-1}$ showed best agreement with the MIPAS measurements when spectroscopic data of NAT were used to simulate the MIPAS spectra. MIPAS measurements collocated with Lidar observations of Type $1 \mathrm{~b}$ and Type 2 PSCs could only be reproduced by assuming a composition of supercooled ternary $\mathrm{H}_{2} \mathrm{SO}_{4} / \mathrm{HNO}_{3} / \mathrm{H}_{2} \mathrm{O}$ solution (STS) and of ice, respectively. Particle radius and number density profiles derived from MIPAS were generally consistent with the Lidar observations. Only in the case of ice clouds, PSC volumes are partly underestimated by MIPAS due to large cloud optical thickness in the limb-direction. A comparison of MIPAS cloud composition and Lidar PSC-type determination based on all available MIPAS-Lidar coincident measurements revealed good agreement between PSC-types $1 \mathrm{a}, 1 \mathrm{~b}$ and 2 , and NAT, STS and ice, respectively. We could not find spectroscopic evidence for the presence of nitric acid dihydrate (NAD) from MIPAS observations of PSCs over Antarctica in 2003 .
\end{abstract}

Correspondence to: $\mathrm{M}$. Höpfner

(michael.hoepfner@imk.fzk.de)

\section{Introduction}

Polar stratospheric clouds (PSCs) play an important role in the process of polar ozone depletion (Solomon, 1999). Through heterogeneous reactions they catalyze the conversion of chlorine from reservoir gases like $\mathrm{ClONO}_{2}$ and $\mathrm{HCl}$ into active species which destroy ozone under sunlit conditions. Further, sedimentation of $\mathrm{HNO}_{3}$ containing PSC particles leads to denitrification of the lower stratosphere, preventing fast reformation of $\mathrm{ClONO}_{2}$ from active chlorine.

A classification of PSCs into different types was first achieved by observations with Lidar instruments (Poole and McCormick, 1988; Browell et al., 1990; Toon et al., 1990). Type 2 clouds are characterized by high backscatter and depolarization ratios which are explained by ice particles. Type 1a and $1 \mathrm{~b}$ clouds scatter less light back than Type 2. While 1a PSCs return a depolarized signal with relatively low backscatter ratio, Type $1 \mathrm{~b}$ shows low depolarization and higher backscatter ratio, indicating large crystalline and small liquid particles, respectively.

In-situ (Fahey et al., 1989; Arnold et al., 1989) and remote sensing (Toon et al., 1989; Santee et al., 1998; Höpfner et al., 1996) measurements of total reactive nitrogen or gaseous $\mathrm{HNO}_{3}$ have demonstrated that PSCs contain nitrate. Laboratory measurements and model calculations have shown that Type $1 \mathrm{~b}$ particles most likely consist of supercooled ternary solution droplets of $\mathrm{H}_{2} \mathrm{SO}_{4} / \mathrm{HNO}_{3} / \mathrm{H}_{2} \mathrm{O}$ (STS) (Zhang et al., 1993; Carslaw et al., 1994; Tabazadeh et al., 1994) while nitric acid trihydrate (NAT) and other metastable hydrates of $\mathrm{HNO}_{3}$ like nitric acid dihydrate (NAD) are candidates for Type 1a PSCs (Hanson and Mauersberger, 1988; Worsnop et al., 1993).

Published by Copernicus GmbH on behalf of the European Geosciences Union. 
There exist very few direct measurements of the composition of PSC particles. In situ PSC measurements using balloon-borne mass spectrometers in the Arctic are consistent with either STS (Schreiner et al., 1999) or NAT (Voigt et al., 2000). However, these data were acquired within mountain wave-induced PSCs, so the findings cannot necessarily be generalized to the synoptic-scale PSCs that exist over large areas of Antarctica which experience much slower local heating and cooling rates (Schreiner et al., 1999). Thus, the composition of Type 1a PSCs is still not clarified completely (Tolbert and Toon, 2001).

A global view of PSC distribution is provided by satelliteborne observations. The Stratospheric Aerosol Measurement (SAM) II instrument was the first to measure the development of PSCs over the Arctic and Antarctic (McCormick, 1981). In these measurements PSC Types 1a and $1 \mathrm{~b}$ could not be distinguished since the extinction had been measured in only one band in the near infrared (IR) at around $1 \mu \mathrm{m}$. Subsequent space-borne limb sounding UV/visible/near-IR instruments like POAM (Polar Ozone and Aerosol Measurements) (Strawa et al., 2002), SAGE (Stratospheric Aerosol and Gas Experiment) (Poole et al., 2003), SCIAMACHY (Scanning Imaging Absorption Spectrometer for Atmospheric Cartography) (von Savigny et al., 2005) or GOMOS (Global Ozone Monitoring by Occultation of Stars) (Vanhellemont et al., 2005) allow to obtain spectrally resolved measurements of PSCs. In case of POAM and SAGE, methods have been developed to discriminate between Type 1 PSCs on basis of different spectral channels in the visible and the near IR (Strawa et al., 2002; Poole et al., 2003). These methods rely on the assumption that Type $1 \mathrm{~b}$ PSC particles are generally smaller than those of Type 1a, which results in a different wavelength dependence of the extinction coefficients.

Complementary to these size distribution-based methods, spectroscopic measurements in the mid-IR allow a distinction of PSC types on basis of their chemical composition by specific vibrational bands. Based on comprehensive laboratory investigations on refractive index data for possible PSC compositions (Toon et al., 1994) and aircraft-borne solar absorption measurements over Antarctica, NAT was ruled out as the likely composition of the observed PSCs (Toon and Tolbert, 1995). On the other hand, space-borne mid-infrared limb-emission observations over Antarctica by the CRyogenic Infrared Spectrometers and Telescopes for the Atmosphere (CRISTA) showed a distinctive spectral signature at around $820 \mathrm{~cm}^{-1}$ which was attributed to NAT through the observed temperature dependence (Spang and Remedios, 2003). However, this strong band could not be reproduced subsequently by available laboratory spectroscopic data on NAT. Also Höpfner et al. (2002) have reported a specific feature at $820 \mathrm{~cm}^{-1}$ in mid-IR spectra measured by the balloonborne version of the Michelson Interferometer for Passive Atmospheric Sounding (MIPAS-B) which is also present in observations by the space-borne MIPAS on Envisat (Höpfner et al., 2004). Finally, Spang et al. (2005) found in a first comparison reasonable agreement between PSC-Type differentiation in MIPAS observations based on the $820 \mathrm{~cm}^{-1}$ band and SAGE III PSC type assignment in the Arctic winter 2002/2003.

We have analyzed measurements of PSCs by MIPAS during the Antarctic stratospheric winter 2003 when an aerosol Lidar at McMurdo station also had acquired data. MIPAS/Lidar coincidences for which the Lidar had identified PSCs of uniform cloud type over its entire altitude range were chosen to test the identification of PSC particle composition using collocated MIPAS observations. Detailed spectroscopic radiative transfer calculations, including new refractive index data for NAT, were used for comparison with the MIPAS observations. MIPAS-derived PSC-types have been compared with Lidar measurements over the whole Antarctic winter. Finally, we show results of an attempt to detect also nitric acid dihydrate (NAD) in MIPAS measurements.

\section{Instruments}

\subsection{MIPAS}

MIPAS on Envisat (Fischer and Oelhaf, 1996; ESA, 2000) is a limb-sounding spectrometer which detects the radiation from trace gases and particles in the atmosphere between 685 and $2410 \mathrm{~cm}^{-1}$ with an unapodized spectral resolution of $0.025 \mathrm{~cm}^{-1}(20 \mathrm{~cm}$ maximum optical path difference of the interferometer). The field-of-view is $30 \mathrm{~km}$ in the horizontal and about $3 \mathrm{~km}$ in the vertical at the tangent points. One limb scan of the standard observation mode covers the altitude range of 6-68 km in 17 steps with tangent altitude increments of $3 \mathrm{~km}$ for the 13 lower tangent altitudes, followed by $47 \mathrm{~km}, 52 \mathrm{~km}, 60 \mathrm{~km}$ and $68 \mathrm{~km}$. These measurements cover the whole latitude band from pole to pole with 14.3 orbits per day and about 73 limb scans along one orbit. Sensitivity on optically thin clouds due to the long limb-pathway in combination with independence from any external light source enables, even at polar night, continuous observations of PSCs with full coverage of the Arctic and Antarctic regions.

During the period from mid-May until mid-October 2003 MIPAS operated quasi-continuously, with the exception of the periods 19-20 May, 25 May-4 June and 5-7 September, where no data are available. MIPAS observed PSCs in the Antarctic stratosphere during all days from 21 May until 15 October. The analysis in this paper is based on MIPAS spectra versions 4.57 and 4.59 .

\subsection{Lidar}

The Lidar measurements which we used for selection and comparison with MIPAS data were performed from McMurdo Station (Ross Island, $77.9^{\circ} \mathrm{S} / 166.7^{\circ} \mathrm{E}$ ). The Lidar, 
which is in operation for PSC monitoring since 1993, is a $\mathrm{Nd}$ :YAG system running at a wavelength of $532 \mathrm{~nm}$ (Adriani et al., 1992, 2004) where backscatter and depolarization data are acquired.

During the PSC period 2003 the Lidar operated from 22 May until 29 September. Due to instrumental problems from 4-11 June no depolarization measurements were possible. First PSCs over McMurdo were detected by 2 June and last ones on 19 September.

\section{Spectroscopic analysis of selected MIPAS/Lidar coin- cidences}

\subsection{Refractive indices}

For modelling of MIPAS mid-IR spectra of PSCs, refractive index data from laboratory investigations are needed. Here, we give a short overview of available optical constants and describe a new set of refractive indices for NAT.

Koehler et al. (1992) distinguished between two phases of crystalline NAT: $\alpha$-NAT forms at temperatures below $185 \mathrm{~K}$ and und transforms irreversibly into $\beta$-NAT above about $188 \mathrm{~K}$. Out of the gas-phase, $\beta$-NAT even crystallizes above $183 \mathrm{~K}$ (Tisdale et al., 1999). Thus, while $\alpha$-NAT is metastable, $\beta$-NAT is the stable phase of NAT. Toon et al. (1994) provided the first optical constants of NAT in the IR. These were obtained by measuring the transmission through thin films, which were condensed out of the gas-phase at temperatures of $181 \mathrm{~K}$ for $\alpha$-NAT and $196 \mathrm{~K}$ for $\beta$-NAT. A second set of refractive indices for $\alpha$-NAT was determined by Richwine et al. (1995) through measurement of the extinction of particles nucleated homogeneously out of the gas phase at $160 \mathrm{~K}$.

Figure $1 \mathrm{~A}$ shows the imaginary parts of the refractive indices for the $\alpha$-NAT data sets. The largest differences in the Toon et al. (1994) data compared to Richwine et al. (1995) are (1) the stronger absorption of the $v_{3}$-band of $\mathrm{NO}_{3}^{-}$at $1390 \mathrm{~cm}^{-1}$, (2) the missing $\nu_{2}$-band of $\mathrm{H}_{3} \mathrm{O}^{+}$at $1120 \mathrm{~cm}^{-1}$, and (3) the much weaker $\nu_{2}$-band of $\mathrm{NO}_{3}^{-}$at $820 \mathrm{~cm}^{-1}$. To investigate these differences, Tisdale et al. (1999) measured absorption spectra of $\alpha$-NAT films formed at different temperatures. They showed that the spectrum observed at $162 \mathrm{~K}$ fitted better to the Richwine et al. (1995) data while at $180 \mathrm{~K}$ the measurement was more consistent with Toon et al. (1994). Tisdale et al. (1999) discussed two possible explanations for this observation: (1) there could exist spectroscopically different forms of $\alpha$-NAT dependent on the temperature, or (2) $\alpha$-NAT could be birefringent. Tisdale et al. (1999) concluded that in case of (1), for interpretation of PSC observations the optical constants by Toon et al. (1994) would be more suitable since these were measured at realistic temperatures. In case (2) none of the two datasets would be appropriate and it would be extremely difficult to reproduce real PSC observations by simulations.

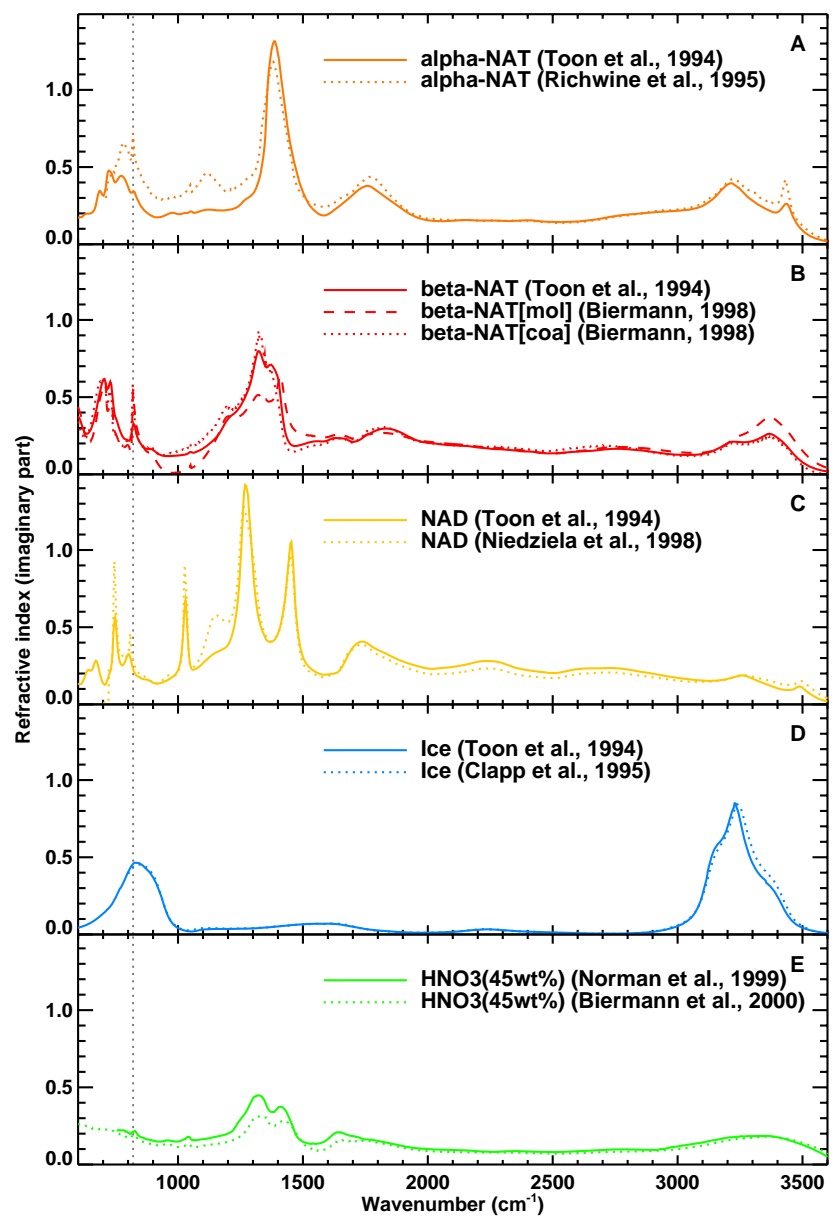

Fig. 1. Refractive indices for different PSC-candidate compositions from various laboratory studies.

We assume, however, that it is more likely that in the stratosphere the metastable $\alpha$-NAT is converted to $\beta$-NAT or that $\beta$-NAT is formed directly. Figure 1B shows to our knowledge the only published optical constants of $\beta$-NAT (Toon et al., 1994). We derived two further sets of refractive indices for $\beta$-NAT from the work of Biermann (1998). Experimental details are described in Appendix A.

For the first measurement (labelled $\beta$-NAT[mol] in Fig. 1B) NAT was crystallized out of a 1:3 stoichiometric solution of $\mathrm{HNO}_{3}: \mathrm{H}_{2} \mathrm{O}\left(53.8 \mathrm{wt} \% \mathrm{HNO}_{3}\right)$ in a low-temperature transmission cell. For the second data set ( $\beta$-NAT[coa]) NAT has been co-condensed together with ice out of the gas phase below the ice frost-point in a reflection absorption cell. After warming up to temperatures above the frost-point but still below the NAT existence temperature, pure NAT was grown from the gas-phase. Apart from a few differences, both measurements were attributed to $\beta$-NAT (Biermann, 1998) due to the stretching mode of $\mathrm{OH}$ at $3375 \mathrm{~cm}^{-1}$, the stretching mode of the $\mathrm{H}_{3} \mathrm{O}^{+}$ion at $2750 \mathrm{~cm}^{-1}$, the bending mode of $\mathrm{H}_{3} \mathrm{O}^{+}$at $1850 \mathrm{~cm}^{-1}$, and the asymmetric stretching mode of 


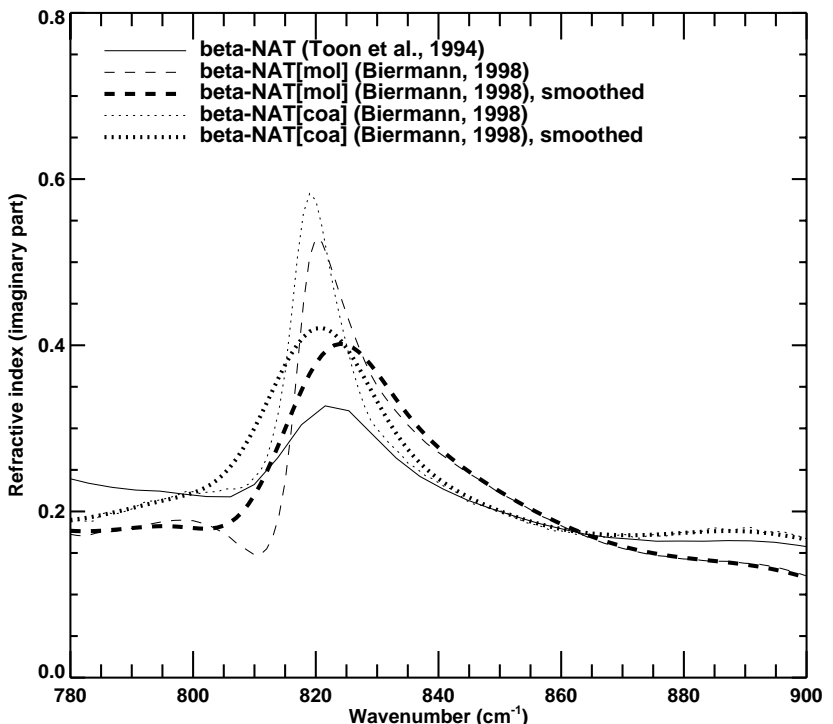

Fig. 2. The effect of reduced spectral resolution on refractive indices of $\beta$-NAT in the region of the $\nu_{2}$-band of $\mathrm{NO}_{3}^{-}$. Biermann (1998)'s data which have been obtained with a resolution of $1 \mathrm{~cm}^{-1}$ have been smoothed to be comparable with the measurements by Toon et al. (1994).

the $\mathrm{NO}_{3}^{-}$ion at $1375 \mathrm{~cm}^{-1}$. From the $\beta$-NAT transmission spectra we derived refractive indices as described by Biermann et al. (2000). However, since the thickness of the NATfilm is not well known, it has been determined by a fit to the $\beta$-NAT data of Toon et al. (1994). The resulting absolute uncertainty in film thickness and, thus, in the refractive index is estimated to $\pm 30 \%$ (Biermann, 1998) (Appendix A).

An important aspect regarding the present work is the large intensity of the $v_{2}$-band of $\mathrm{NO}_{3}^{-}$(Ritzhaupt and Devlin, 1991) at $820 \mathrm{~cm}^{-1}$ compared to the previously reported optical constants by Toon et al. (1994). Figure 2 shows this wavenumber region in detail. For comparing the spectra of such a relatively narrow band the spectral resolution of the measurements must be taken into account. While Biermann (1998) obtained the data with a resolution of $1 \mathrm{~cm}^{-1}$, Toon et al. (1994) measured with $8 \mathrm{~cm}^{-1}$. Thus, we degraded the new $\beta$-NAT indices to be consistent with the coarser spectral resolution. As shown in Fig. 2 the shape of the bands becomes more similar. The maximum intensity of the absorption feature is reduced by $40 \%$, which is, however, still about a factor of 1.7 stronger than the observations by Toon et al. (1994). The reason for this is unknown. The spectral location of the $\nu_{2}\left(\mathrm{NO}_{3}^{-}\right)$band for NAT at $820 \mathrm{~cm}^{-1}$ is reported consistently in various laboratory studies as listed in Table 1 .

In Fig. 1C we present available refractive indices for NAD by Toon et al. (1994) and Niedziela et al. (1998). Tisdale et al. (1999) attributed the differences to the existence of various NAD crystal structures depending on the formation conditions. However, these differences are more likely explained by the existence of two modifications of NAD (Lebrun et al., 1996; Tizek et al., 2002). First infrared spectra of $\alpha$-NAD and $\beta$-NAD were published by Grothe et al. (2004) who have noted that probably most of the previously published NAD spectra were from $\alpha$-NAD or mixtures of $\alpha$ - and $\beta$-NAD. Comparison of the optical constants of NAD by Niedziela et al. (1998) and Toon et al. (1994), which we have used for our simulations, with the Grothe et al. (2004) measurements shows much better agreement with $\alpha$-NAD than with $\beta$-NAD (Wagner et al., 2005).

Figure 1D shows that refractive indices for ice are well known and, thus, are reliable for use in radiative transfer modelling.

Refractive indices for STS can be calculated by application of a mixing rule to the binary solutions of $\mathrm{H}_{2} \mathrm{SO}_{4} / \mathrm{H}_{2} \mathrm{O}$ and of $\mathrm{HNO}_{3} / \mathrm{H}_{2} \mathrm{O}$ (Biermann et al., 2000). For volcanically unperturbed stratospheric conditions as in the case of the MIPAS observations in 2003, mainly the refractive index of $\mathrm{HNO}_{3} / \mathrm{H}_{2} \mathrm{O}$ determines the optical constants of STS PSCs with volume densities $\geq 1 \mu \mathrm{m}^{3} \mathrm{~cm}^{-3}$. As an example in Fig. 1E we show refractive indices for $45 \mathrm{wt} \%$ solutions of $\mathrm{HNO}_{3} / \mathrm{H}_{2} \mathrm{O}$ by Biermann et al. (2000) and by Norman et al. (1999). Wagner et al. (2003) attributed the differences in band intensity between 1000 and $1700 \mathrm{~cm}^{-1}$ to a simplified analysis of the thin film spectra in Biermann et al. (2000). Errors induced by the assumption of the mixing rule have not been quantified so far. Norman et al. (2002) found that the differences between their measurements of ternary solutions and calculations based on the Biermann et al. (2000) data and the mixing rule were mainly caused by the binary datasets for $\mathrm{HNO}_{3} / \mathrm{H}_{2} \mathrm{O}$ and $\mathrm{H}_{2} \mathrm{SO}_{4} / \mathrm{H}_{2} \mathrm{O}$ of Biermann et al. (2000). This was also suggested by Wagner et al. (2003). Using their own data for $\mathrm{HNO}_{3} / \mathrm{H}_{2} \mathrm{O}$ (Norman et al., 1999) and $\mathrm{H}_{2} \mathrm{SO}_{4} / \mathrm{H}_{2} \mathrm{O}$ (Niedziela et al., 1999), combined with the mixing rule by Biermann et al. (2000), the agreement between calculation and measurement of ternary solutions improved considerably (Norman et al., 2002). Remaining differences were attributed to the mixing rule itself. Also, Lund Myhre et al. (2005) report on differences between their spectra of ternary solutions and mixing-rule calculations based on their own binary dataset. These differences are explained by interference of the dissociation equilibria of $\mathrm{HNO}_{3}$ and $\mathrm{H}_{2} \mathrm{SO}_{4}$ (Minogue, 2003; Lund Myhre et al., 2005).

To simulate STS PSCs within MIPAS spectra, we calculated refractive indices using the mixing rule by combining different sets of binary optical constants: (1) those provided by Biermann et al. (2000), and (2) $\mathrm{HNO}_{3} / \mathrm{H}_{2} \mathrm{O}$ by (Norman et al., 1999) combined with $\mathrm{H}_{2} \mathrm{SO}_{4} / \mathrm{H}_{2} \mathrm{O}$ by Niedziela et al. (1999).

\subsection{Radiative transfer and retrieval model}

To calculate the radiative transfer of mid-IR limb measurements of PSCs it is necessary to account for radiation from the earth's surface and the troposphere which is scattered by 
Table 1. Positions of the $v_{2}$-band of $\mathrm{NO}_{3}^{-}$for NAD and NAT from literature.

\begin{tabular}{lll}
\hline Reference & NAD & NAT \\
\hline $\begin{array}{l}\text { Biermann (1998) } \\
\text { Grothe et al. (2004) }\end{array}$ & $809 \mathrm{~cm}^{-1}(\alpha), 811 \mathrm{~cm}^{-1}(\beta)$ & $819 \mathrm{~cm}^{-1}(\beta[$ coa $]), 820 \mathrm{~cm}^{-1}(\beta[\mathrm{mol}])$ \\
Hudson et al. (2002) & & $820 \mathrm{~cm}^{-1}(\alpha)$ \\
Koch et al. (1996) & $808 \mathrm{~cm}^{-1}$ (RAIRS), $808 \mathrm{~cm}^{-1}$ (trans) & $821 \mathrm{~cm}^{-1}$ (RAIRS), $820 \mathrm{~cm}^{-1}$ (trans) \\
Niedziela et al. (1998) & $808 \mathrm{~cm}^{-1}$ & $820 \mathrm{~cm}^{-1}(\alpha)$ \\
Richwine et al. (1995) & & $820 \mathrm{~cm}^{-1}$ \\
Ritzhaupt and Devlin (1991) & $809 \mathrm{~cm}^{-1}$ & $820 \mathrm{~cm}^{-1}(\alpha)$ \\
Tisdale et al. (1999) & & $821 \mathrm{~cm}^{-1}(\alpha), 821 \mathrm{~cm}^{-1}(\beta)$ \\
Toon et al. (1994) & $802 \mathrm{~cm}^{-1}$ & \\
\hline
\end{tabular}

RAIRS: reflection/absorption infrared spectroscopy; trans: transmission spectra

the particles into the direction of the instrument (Höpfner et al., 2002). We use the Karlsruhe Optimized and Precise Radiative transfer Algorithm (KOPRA) for the simulation of MIPAS/Envisat measurements (Höpfner, 2004). This code, which includes single scattering for a curved atmosphere, has been validated by comparison with a multiple scattering model (Höpfner and Emde, 2004). There it has been shown that clouds with IR limb optical thickness of PSCs can be modelled by single scattering within an error of a few percent.

KOPRA is embedded in a retrieval environment which allows direct derivation of microphysical properties of particles from radiance spectra (Höpfner et al., 2002). Altitude dependent lognormal particle size distributions are used defined by number density $(N(h))$, median radius $\left(r_{m}(h)\right)$ and geometric standard deviation $\sigma(h)$ :

$n(r, h)=\frac{N(h)}{r \ln (\sigma(h)) \sqrt{2 \pi}} \exp \left[-\frac{\ln ^{2}\left(r / r_{m}(h)\right)}{2 \ln ^{2}(\sigma(h))}\right]$,

where $r$ is the particle radius and $h$ the altitude.

Atmospheric profiles of aerosol parameters or trace gases are represented by the vector of unknown parameters, $\boldsymbol{x}$, which is determined in a Newtonian iteration process to account for the nonlinearity of the atmospheric radiative transfer (Rodgers, 2000; von Clarmann et al., 2003):

$\boldsymbol{x}_{i+1}=\boldsymbol{x}_{i}+\left(\mathbf{K}^{T} \mathbf{S}_{y}^{-1} \mathbf{K}+\mathbf{R}\right)^{-1} \times\left(\mathbf{K}^{T} \mathbf{S}_{y}^{-1}\left(\boldsymbol{y}_{\text {meas }}-\boldsymbol{y}\left(\boldsymbol{x}_{i}\right)\right)\right.$

$\left.-\mathbf{R}\left(\boldsymbol{x}_{i}-\boldsymbol{x}_{a}\right)\right)$.

$\boldsymbol{y}_{\text {meas }}$ is the vector of selected measured spectral radiances of all tangent altitudes under investigation, and $\mathbf{S}_{y}$ is the related noise covariance matrix. $\boldsymbol{y}\left(\boldsymbol{x}_{i}\right)$ contains the spectral radiances calculated by the radiative transfer model using the best guess atmospheric state parameters $\boldsymbol{x}_{i}$ of iteration number $i$. $\mathbf{K}$ is the Jacobian matrix, i.e. the partial derivatives $\partial \boldsymbol{y}\left(\boldsymbol{x}_{i}\right) / \partial \boldsymbol{x}_{i} . \mathbf{R}$ is a regularization matrix and $\boldsymbol{x}_{a}$ the a-priori information.

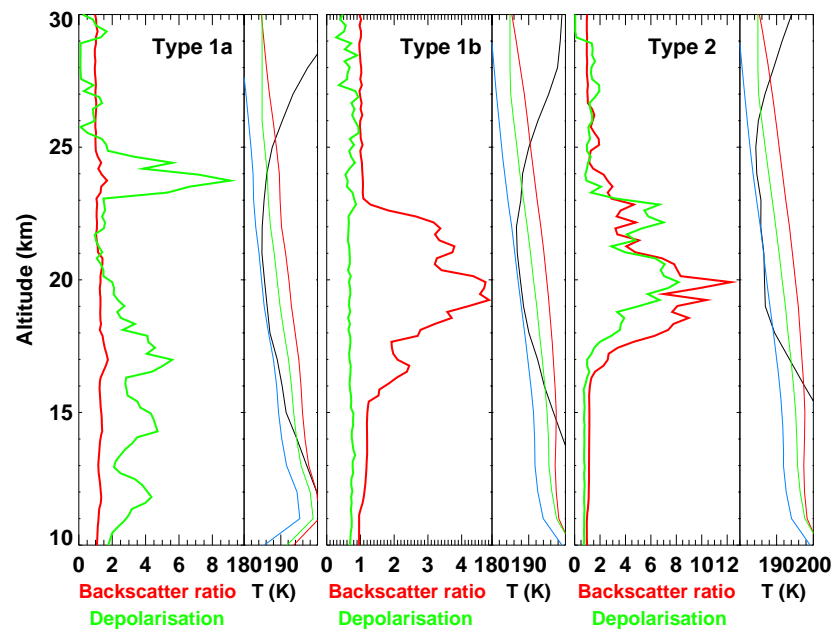

Fig. 3. Backscatter ratio and depolarization profiles of three Lidar measurements of different PSC Types which were selected for analysis of PSCs from matching MIPAS limb-scans (see Table 2). Corrected ECMWF temperature profiles are black (see text and Appendix B for details). Existence temperatures are colour-coded: blue for ice, green for STS, and red for NAT.

\subsection{Data analysis}

To deal with rather uniform PSC types for the spectroscopic analysis we have selected three MIPAS/Lidar coincidences in which the Lidar identified PSCs of either Type 1a, Type $1 \mathrm{~b}$, or Type 2 over its entire altitude range (see Table 2). Lidar backscatter and depolarization ratios for these examples are plotted in Fig. 3. In parallel to the Lidar measurements, Fig. 3 shows temperature profiles in comparison with existence temperatures for ice, STS, and NAT. The temperature profiles were interpolated from ECMWF analyses to the time and location of the Lidar measurements. Additionally, we have corrected these temperatures for a systematic altitudedependent bias derived from comparison between ECMWF and McMurdo sonde data (see Appendix B). 
Table 2. Selected matches between PSC observations by Lidar from McMurdo $\left(77.9^{\circ} \mathrm{S} / 166.7^{\circ} \mathrm{E}\right)$ and by MIPAS from Envisat.

\begin{tabular}{llll}
\hline PSC Type & $\begin{array}{l}\text { Lidar } \\
\text { date/time(UT) }\end{array}$ & $\begin{array}{l}\text { MIPAS } \\
\text { date/time(UT)/lat/lon }\end{array}$ & $\begin{array}{l}\text { Distance } \\
{[\mathrm{km}]}\end{array}$ \\
\hline 1a & 4 August 2003/08:14 & 4 August 2003/12:02/-76.3/166.6 & 178 \\
1b & 15 June 2003/00:54 & 14 June 2003/22:01/-78.5/169.4 & 91 \\
2 & 21 June 2003/02:20 & 20 June 2003/22:13/-77.5/167.6 & 49 \\
\hline
\end{tabular}

Table 3. Broad-band root-mean-squares difference between simulation and measurement for the two channels of Fig. 4 (Lidar Type 1a case) normalized by the spectral noise.

\begin{tabular}{lccc}
\hline Source of refractive index & Mean radius $(\mu \mathrm{m})$ & \multicolumn{2}{c}{ Broad band normalized rms } \\
& & 780-960 $\mathrm{cm}^{-1}$ & 1220-1490 $\mathrm{cm}^{-1}$ \\
\hline$\beta$-NAT (Toon et al., 1994) & 0.8 & 29.2 & 4.5 \\
$\beta$-NAT[coa] (Biermann, 1998) & 0.8 & 16.5 & 4.3 \\
$\beta$-NAT[mol] (Biermann, 1998) & 0.8 & 30.6 & 8.3 \\
$\beta$-NAT[mol] (Biermann, 1998) & 1.5 & 15.6 & 9.6 \\
$\alpha$-NAT (Toon et al., 1994) & 0.8 & 20.5 & 16.5 \\
$\alpha$-NAT (Richwine et al., 1995) & 0.8 & 18.6 & 9.5 \\
NAD (Toon et al., 1994) & 0.2 & 43.1 & 12.6 \\
NAD (Niedziela et al., 1998) & 0.2 & 33.9 & 11.0 \\
Ice (Toon et al., 1994) & 5.0 & 39.1 & 16.6 \\
STS (Biermann et al., 2000) & 0.5 & 20.5 & 14.7 \\
STS (Norman et al., 1999; Niedziela et al., 1999) & 0.5 & 21.4 & \\
\hline
\end{tabular}

The altitude region where PSCs are expected from the temperature profiles were in general consistent with the Lidar data. For STS and NAT the temperatures were above the ice frost point. For the case of Type 2 PSCs the temperatures were at or below the ice frost point for the most part of the cloud. Only in the upper part of this profile temperatures were above the frost point by about $1 \mathrm{~K}$. However, the high Lidar backscattering there (together with the strongly enhanced MIPAS infrared radiances) clearly show that ice was present also at these altitudes. This conflict be explained by a remaining uncertainty in the corrected temperature profile.

The chemical composition of the three selected PSC cases then was spectroscopically analyzed using the collocated MIPAS observations. Following the scheme in Höpfner et al. (2002) we first determined altitude profiles of particle number density $(N(h)$ in Eq. 1) under the assumption of various height-constant median radii $r_{m}$ and a height-constant $\sigma=1.35$ by non-linear least squares fitting of the MIPAS limb radiances in spectral windows centred at around $830 \mathrm{~cm}^{-1}$, $950 \mathrm{~cm}^{-1}$ and $1220 \mathrm{~cm}^{-1}$ where trace-gas interference is low. The retrieval was performed on a $1 \mathrm{~km}$ grid between 12 and $29 \mathrm{~km}$ altitude with $\mathbf{R}$ chosen as a 1 st order smoothing constraint (Steck, 2002), and an initial guess $\boldsymbol{x}_{0}$ and a-priori $\boldsymbol{x}_{a}$ equal zero. The regularization strength was chosen such that five degrees-of-freedom were achieved. This is equivalent to an altitude resolution of about $3.4 \mathrm{~km}$ in terms of the full width at half maximum of the related column of the averaging kernel matrix

$\mathbf{A}=\left(\mathbf{K}^{T} \mathbf{S}_{y}^{-1} \mathbf{K}+\mathbf{R}\right)^{-1} \mathbf{K}^{T} \mathbf{S}_{y}^{-1} \mathbf{K}$.

In this manner, for all sets of refractive indices described in Sect. 3.1, number density profiles were determined for various height-constant $r_{m}$ between 0.2 and $9 \mu \mathrm{m}$. The $r_{m}$ with best agreement between observation and measurement, was then used for the further broad-band calculations as described below.

For STS we determined the altitude dependent refractive indices by using the mixing rule of Biermann et al. (2000). STS particle composition was calculated from thermodynamic equilibrium (Carslaw et al., 1994) based on ECMWF temperature analysis, 4-10 ppbv $\mathrm{HNO}_{3}, 3-5$ ppmv $\mathrm{H}_{2} \mathrm{O}$ and 0.3 ppbv $\mathrm{H}_{2} \mathrm{SO}_{4}$. The resulting altitude profiles of PSC number densities will be discussed and compared with the collocated Lidar observations in Sect. 3.4.

Subsequently we determined abundances of trace gases with major spectroscopic signatures in the MIPAS channels used $\left(\mathrm{O}_{3}, \mathrm{H}_{2} \mathrm{O}, \mathrm{N}_{2} \mathrm{O}, \mathrm{CH}_{4}, \mathrm{HNO}_{3}, \mathrm{CFC}-11\right)$ within specific spectral windows. Using these trace gas profiles together with the number densities and mean radii for which the best fit between radiative transfer calculations and measurements 
was obtained, we performed broadband spectral calculations for each refractive index data set.

Figure 4 shows results of such a calculation in comparison with MIPAS for a coincident MIPAS/Lidar measurement where the Lidar observed a PSC of Type 1a. We also show a PSC-free spectrum taken just northwards (black dotted line in 5th row of Fig. 4) to demonstrate the effect of PSCs on the radiances and to indicate the spectral influence of trace gas contribution. A strong spectral signature emitted by PSC particles is present in the MIPAS PSC spectrum at around $820 \mathrm{~cm}^{-1}$, clearly distinguishable from any trace gas signature nearby: $\mathrm{CCl}_{3} \mathrm{~F}(\mathrm{CFC}-11)$ at $830-860 \mathrm{~cm}^{-1}$, $\mathrm{CHClF}_{2}(\mathrm{HCFC}-22)$ at $809 \mathrm{~cm}^{-1}, \mathrm{O}_{3}, \mathrm{CO}_{2}, \mathrm{CCl}_{4}$ at around $798 \mathrm{~cm}^{-1}$, and $\mathrm{a} \mathrm{CO}_{2}$ Q-branch at $792 \mathrm{~cm}^{-1}$.

This PSC feature can be reproduced using both sets of refractive indices for $\beta$-NAT derived from Biermann (1998). From these, $\beta$-NAT[coa] resulted in the best fit using a median particle radius of $0.8 \mu \mathrm{m}$. $\beta$-NAT[mol], for which the best fit has been obtained with a particle radius of $1.5 \mu \mathrm{m}$, reproduces the $820 \mathrm{~cm}^{-1}$ feature and the wavenumber region above about $1300 \mathrm{~cm}^{-1}$ slightly worse. The sensitivity of the fit on particle size is demonstrated by also showing the calculated spectrum for $0.8 \mu \mathrm{m}$ in Fig. 4 which strongly deviates from the measurement between 900 and $960 \mathrm{~cm}^{-1}$.

Refractive indices of $\alpha$-NAT by Richwine et al. (1995) and $\beta$-NAT by Toon et al. (1994) provide a signature at around $820 \mathrm{~cm}^{-1}$, but of much weaker intensity. Spectroscopic data of NAD, STS, and ice show no evidence of the observed spectral band. In the second column of Table 3 we list the root-mean-square differences between the simulations and the measurement normalized by the instrumental noise for the longwave spectral range $\left(780-960 \mathrm{~cm}^{-1}\right)$ shown in Fig. 4. These numbers support our conclusions drawn from inspection of the $820 \mathrm{~cm}^{-1}$ band alone: best agreement is found for the new $\beta$-NAT refractive index data, followed by $\alpha$-NAT of Richwine et al. (1995).

This agrees with simulations in the shorter wavelength channel B of MIPAS (see right part of Fig. 4). The noiseweighted root-mean-square differences for this range are given in Table 3. Here the refractive index datasets $\beta$ NAT[coa] from Biermann (1998) and $\beta$-NAT by Toon et al. (1994) by far agree best with the observations, followed by $\alpha$-NAT of Richwine et al. (1995) and $\beta$-NAT[mol] from Biermann (1998). In the region around $1380 \mathrm{~cm}^{-1}$ where the $\nu_{3}$ band of $\mathrm{NO}_{3}^{-}$of $\alpha$-NAT is stronger than that of the $\beta$ modification both $\alpha$-NAT simulations overestimate the measurements. The use of NAD refractive index data results in too high spectral radiances at around $1450 \mathrm{~cm}^{-1}$, where a relatively strong $\mathrm{NO}_{3}^{-} v_{3}$-band is located. Simulations with ice as well as STS do not match well the measurements from 1220 to $1490 \mathrm{~cm}^{-1}$.

Analysis of MIPAS spectra for coincident data where the Lidar observed PSCs of Type $1 \mathrm{~b}$ and 2 are shown in Figs. 5 and 6 , respectively. In both cases the MIPAS measurements do not show a bandlike structure at $820 \mathrm{~cm}^{-1}$.

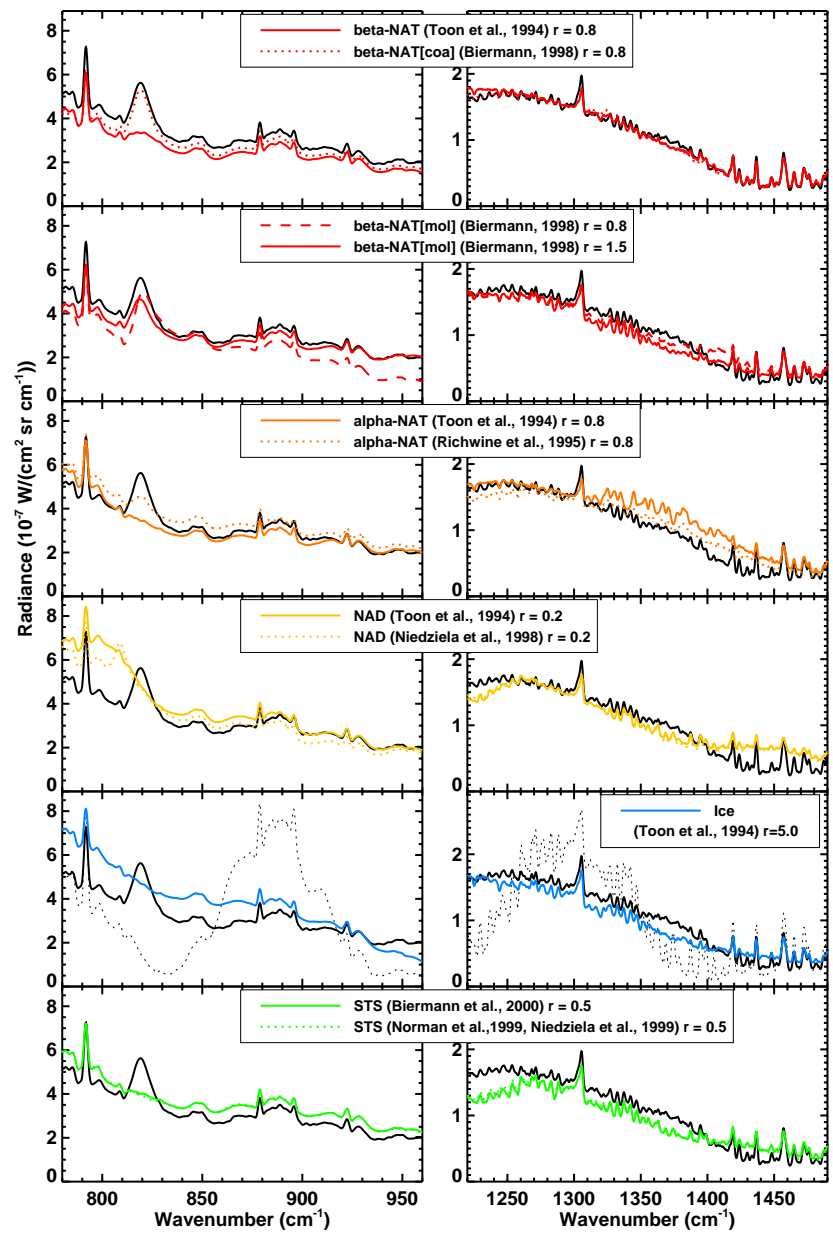

Fig. 4. MIPAS spectra for a tangent altitude of $15.2 \mathrm{~km}$ on $4 \mathrm{Au}-$ gust 2003 (black solid, for exact geolocation see Table 2) in comparison with radiative transfer simulations for different refractive indices (colour) and a nearby PSC-free measurement (black, dotted). For better visibility of the aerosol features the calculated and the MIPAS spectra have been degraded to a resolution of $1 \mathrm{~cm}^{-1}$. The most prominent PSC signature in the MIPAS measurements is at $820 \mathrm{~cm}^{-1}$. This PSC observation occurred close to a Lidar measurement of Type 1a clouds. Simulations shown are those resulting from the best fit of number density and mean radius (as given in the legend) based on log-normal distributions.

For Type $1 \mathrm{~b}$ best fits were obtained over the whole spectral range with refractive indices of STS (Fig. 5 and Table 4). Both sets of refractive indices by Biermann et al. (2000) and Norman et al. (1999)/Niedziela et al. (1999) fit the observations. As listed in Table 4 the broad band rootmean-square difference in the lower wavenumber channel are smallest for the Biermann et al. (2000) data while in the higher wavenumber channel simulations based on Norman et al. (1999)/Niedziela et al. (1999) indices agree best. Thus, it cannot be decided which data set is superior.

In case of the Lidar Type 2 observation, the assumption of ice reproduces the MIPAS spectra best (Fig. 6 and Table 5). 
Table 4. Broad-band root-mean-squares difference between simulation and measurement for the two channels of Fig. 5 (Lidar Type $1 \mathrm{~b}$ case) normalized by the spectral noise.

\begin{tabular}{lccc}
\hline Source of refractive index & Mean radius $(\mu \mathrm{m})$ & \multicolumn{2}{c}{ Broad band normalized rms } \\
& & 780-960 cm & 1220-1490 $\mathrm{cm}^{-1}$ \\
\hline beta-NAT (Toon et al., 1994) & 2.0 & 34.9 & 9.9 \\
beta-NAT[coa] (Biermann, 1998) & 2.0 & 22.9 & 8.4 \\
beta-NAT[mol] (Biermann, 1998) & 2.0 & 28.5 & 7.1 \\
alpha-NAT (Toon et al., 1994) & 0.5 & 17.5 & 21.4 \\
alpha-NAT (Richwine et al., 1995) & 0.5 & 11.3 & 13.0 \\
NAD (Toon et al., 1994) & 5.0 & 12.1 & 13.5 \\
NAD (Niedziela et al., 1998) & 5.0 & 12.6 & 12.9 \\
Ice (Toon et al., 1994) & 5.0 & 19.9 & 6.6 \\
STS (Biermann et al., 2000) & 0.2 & 4.9 & 4.9 \\
STS (Norman et al., 1999; Niedziela et al., 1999) & 0.2 & 6.0 & 3.9 \\
\hline
\end{tabular}

Table 5. Broad-band root-mean-squares difference between simulation and measurement for the two channels of Fig. 6 (Lidar Type 2 case) normalized by the spectral noise.

\begin{tabular}{lccc}
\hline Source of refractive index & Mean radius $(\mu \mathrm{m})$ & \multicolumn{2}{c}{ Broad band normalized rms } \\
& & 780-960 $\mathrm{cm}^{-1}$ & 1220-1490 $\mathrm{cm}^{-1}$ \\
\hline beta-NAT (Toon et al., 1994) & 0.8 & 40.5 & 18.1 \\
beta-NAT[coa] (Biermann, 1998) & 1.0 & 36.9 & 18.9 \\
beta-NAT[mol] (Biermann, 1998) & 1.5 & 36.9 & 11.9 \\
alpha-NAT (Toon et al., 1994) & 0.5 & 34.9 & 10.3 \\
alpha-NAT (Richwine et al., 1995) & 0.5 & 12.2 & 11.1 \\
NAD (Toon et al., 1994) & 5.0 & 26.5 & 30.1 \\
NAD (Niedziela et al., 1998) & 5.0 & 27.3 & 28.7 \\
Ice (Toon et al., 1994) & 5.0 & 9.0 & 5.1 \\
STS (Biermann et al., 2000) & 0.2 & 20.0 & 18.2 \\
STS (Norman et al., 1999; Niedziela et al., 1999) & 0.2 & 15.7 & 17.2 \\
\hline
\end{tabular}

\subsection{Discussion of retrieved PSC altitude profiles}

In case of mid-IR retrieval of properties of small absorbing particles, volume density is the basic parameter. As has been shown in previous studies (Höpfner, 2004), for PSC particles smaller than about $1 \mu \mathrm{m}$ there is little information on particle size and the variables $\left(N(h), r_{m}\right.$ and $\left.\sigma\right)$ of a lognormal distribution are all interdependent. For particles larger than about $1 \mu \mathrm{m}$, some independent information on size can be obtained. This explains why we obtained different spectral fit quality for variation of $r_{m}$ in the examples discussed above. The remaining correlation between $r_{m}$ and $\sigma$, however, hinders an independent retrieval of these parameters (Echle et al., 1998). Thus, without loss of generality for the present analysis, $\sigma$ was kept constant.

Volume density profiles from the previous retrieval can be compared to the volume solid or liquid PSC phases can reach under thermodynamic equilibrium conditions (Hanson and Mauersberger, 1988; Carslaw et al., 1995). We calculated these profiles using temperatures from ECMWF corrected for the altitude dependent bias described in Appendix B and $0.3 \mathrm{ppbv}$ of $\mathrm{H}_{2} \mathrm{SO}_{4}$. For the observations in June (Type $1 \mathrm{~b}$ and Type 2,) mean profiles of water vapour and $\mathrm{HNO}_{3}$ from MIPAS retrievals in May 2003 were used, assuming that no denitrification had taken place. Calculated and retrieved volume densities fit reasonably well in case of the PSC Type 1b observations. Retrieved volume densities from the PSC Type 2 measurements are larger above and smaller below $20 \mathrm{~km}$ compared to those obtained from equilibrium calculations on basis of the corrected ECMWF temperatures. The underestimation at lower altitudes is attributed to ice PSCs becoming close to optically thick in limb direction such that no information can be retrieved any more. Differences at higher altitudes are explained by propagation of the temperature error. Temperatures were close to the ice frost point, and, thus, slight variations have large effects on the estimated volume densities. 


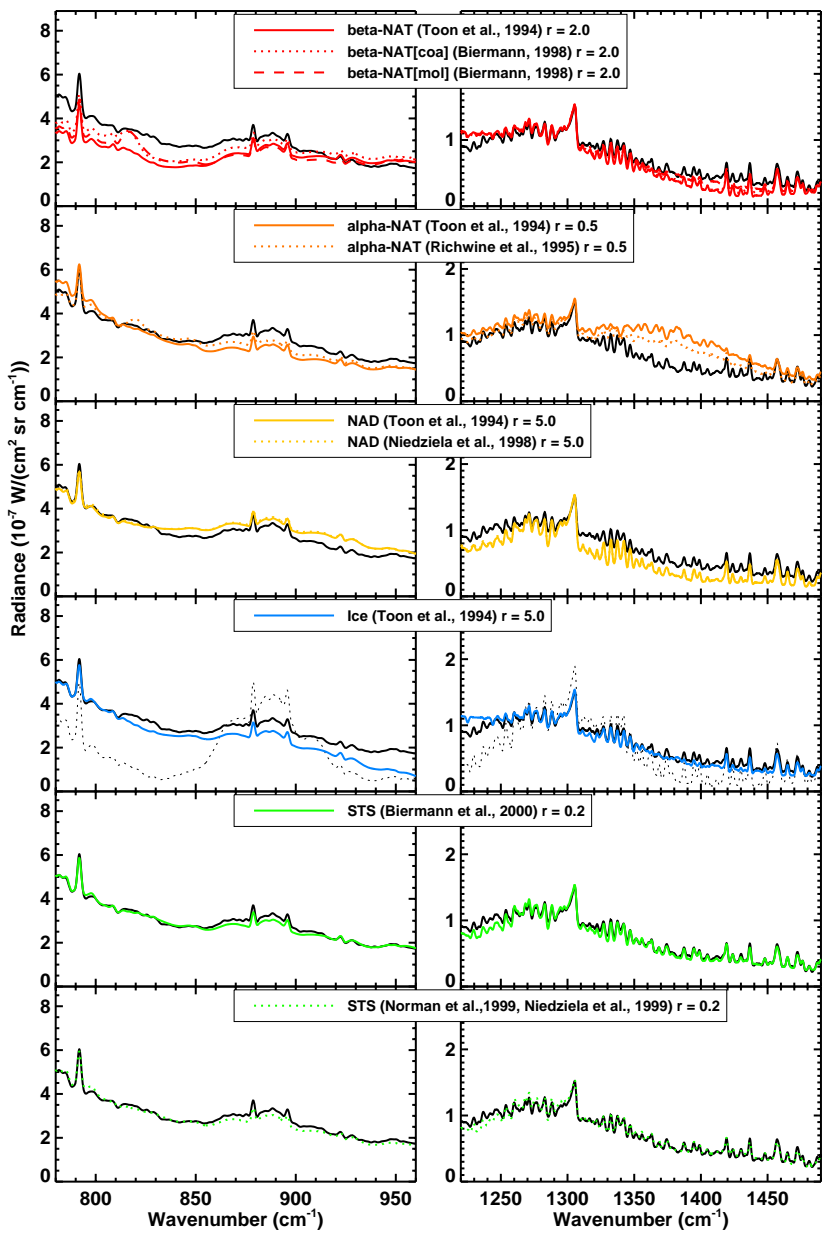

Fig. 5. Same plot as Fig. 4 but for MIPAS spectra on 14 June 2003 for a tangent altitude of $17.3 \mathrm{~km}$ (black) in comparison with radiative transfer simulations for different refractive indices (colour) and a nearby PSC-free measurement (black, dotted). This observation occurred close to a Lidar measurement of Type 1b PSCs.

In the case of the Type 1a observation in August, $\mathrm{HNO}_{3}$ had been depleted due to sedimentation of PSC particles in the previous two months, which explains the low PSC volume densities retrieved above $19 \mathrm{~km}$. A quantitative comparison with equilibrium calculations is, however, difficult since no PSC-free inner vortex MIPAS observations are available to determine the reference gas profiles for use in the equilibrium calculations. To give a qualitative picture, we have used the actual gas-phase $\mathrm{HNO}_{3}$ profile determined from MIPAS to calculate the equilibrium profile. The results agree with the low values measured above about $19-20 \mathrm{~km}$. Below $19 \mathrm{~km}$ the low gas-phase vmr from MIPAS used in the equilibrium calculations result in too small PSC volume densities compared to the measurement. Therefore, at these altitudes the denitrification was smaller than above $19-20 \mathrm{~km}$ and more $\mathrm{HNO}_{3}$ was available for formation of PSCs.

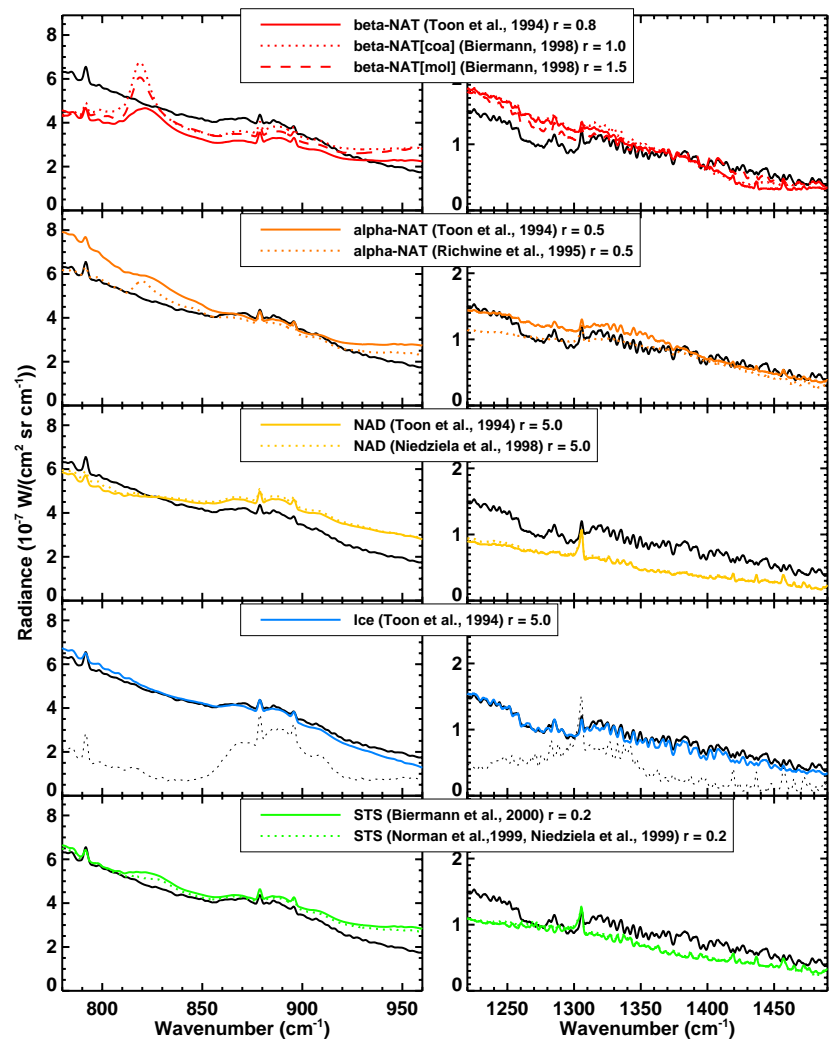

Fig. 6. Same as Fig. 4 but for MIPAS measurements on 20 June 2003 for tangent altitude $23.4 \mathrm{~km}$ (black). The observation occurred near a Lidar measurement of Type 2 PSCs.

To compare MIPAS PSC profiles with the collocated Lidar measurements we determined the aerosol backscatter coefficients at the Lidar wavelength of $532 \mathrm{~nm}$ by Mie calculations using lognormal size distributions with $N(h), r_{m}$ and $\sigma$ from MIPAS. Available refractive indices for PSCs show some variation, especially for NAT and STS. In case of NAT Middlebrook et al. (1994) measured values of 1.51 for $\alpha$ NAT and a lower limit of 1.46 for $\beta$-NAT at $632 \mathrm{~nm}$ in the laboratory. These are consistent with the range of 1.46-1.54 at $532 \mathrm{~nm}$ Deshler et al. (2000) derived from balloon-borne observations of a depolarizing PSC-layer. However, recently Scarchilli et al. (2005) state refractive indices for NAT of 1.37-1.45. For STS Deshler et al. (2000) calculated values in the range $1.43-1.49$ at $532 \mathrm{~nm}$ which is, on average, slightly higher than values expected from theory (1.43) for this observation (Luo et al., 1996). Even higher values for STS have been reported by Larsen et al. (2000): 1.5 at $940 \mathrm{~nm}$, and by Scarchilli et al. (2005): $1.51-1.55$ at $532 \mathrm{~nm}$. Refractive indices for ice are more consistent: e.g. 1.30 (Middlebrook et al., 1994) or 1.31-1.33 (Scarchilli et al., 2005). To cover this variability, we used refractive indices of 1.37-1.54 for Type 1a, $1.43-1.55$ for Type $1 \mathrm{~b}$ and $1.30-1.33$ for Type 2 for the calculations in Fig. 8. 


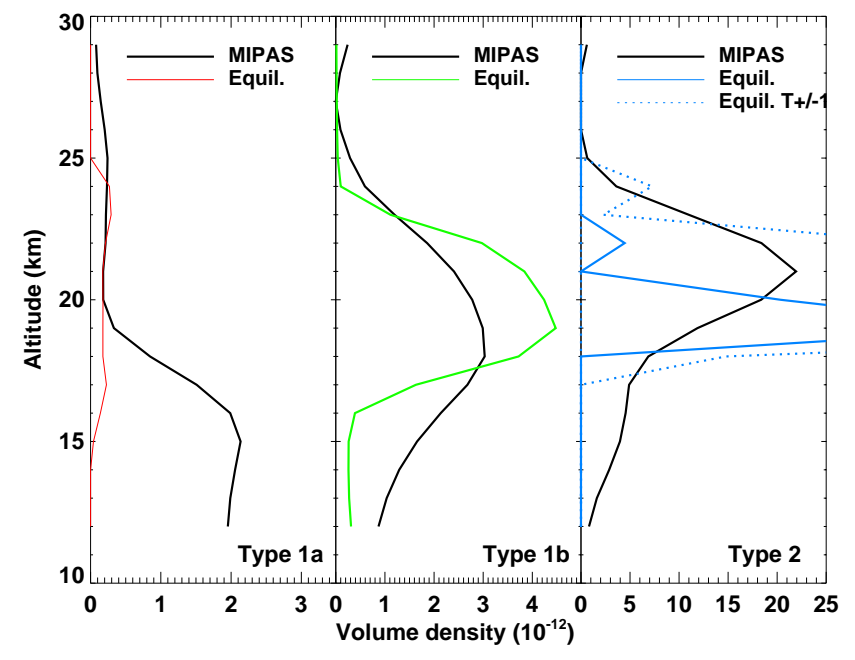

Fig. 7. MIPAS PSC volume density profiles for the collocations with the three different Lidar Type measurements. The results were obtained with the following settings of median radius and refractive indices. Type 1a: $r_{m}=0.8 \mu \mathrm{m}, \beta$-NAT refractive indices by Biermann (1998) and this work; Type $1 \mathrm{~b}: \mathrm{r}=0.2 \mu \mathrm{m}$, refractive indices by Biermann et al. (2000); Type 2: $\mathrm{r}=5.0 \mu \mathrm{m}$, refractive indices by Toon et al. (1994). $\sigma$ was set constant to 1.35 in all cases. Coloured curves are volume density profiles for NAT (red), STS (green), and ice (blue) in thermodynamic equilibrium (see text for details).

In case of the MIPAS-Lidar Type 1a match, backscatter coefficient profiles have been calculated for the MIPAS result of $N(h)$ with $r_{m}=0.8 \mu \mathrm{m}$ which was the best result of radius for the Biermann (1998) [coa] data and $r_{m}=1.5 \mu \mathrm{m}$, the result for the Biermann (1998) [mol] dataset (see Fig. 4). Using the smaller radius the calculated backscatter coefficients exceeded the Lidar data by about a factor of 5 , while for $r_{m}=1.5 \mu \mathrm{m}$ there is good agreement between Lidar and MIPAS (Fig. 8, left panel). This might be an indication that the Biermann (1998) [mol] refractive index dataset is more appropriate for quantitative analysis of MIPAS Type 1a observations.

As mentioned above, there is no independent information on the particle sizes in MIPAS observations of small particles. Therefore, in case of Type 1b PSCs $r_{m}=0.1,0.2$ or even $0.5 \mu \mathrm{m}$ lead to fits between calculated and measured spectra of comparable quality. The middle panel in Fig. 8 shows that the Lidar data can best be reproduced with $r_{m}=0.1 \mu \mathrm{m}$. However, also $r_{m}=0.2 \mu \mathrm{m}$ leads to similar results if the smaller refractive indices from literature (1.43) of STS at $532 \mathrm{~nm}$ are used.

For the example of a Type 2 PSC we already stated that volume density is strongly underestimated due to cloud opacity in limb-direction. This is also the case when comparing the aerosol backscatter coefficients in Fig. 8, right panel. In the centre of the cloud, backscatter coefficients calculated from MIPAS are much lower than Lidar. However, at cloud top, above about $21 \mathrm{~km}$ altitude, calculated and measured co-

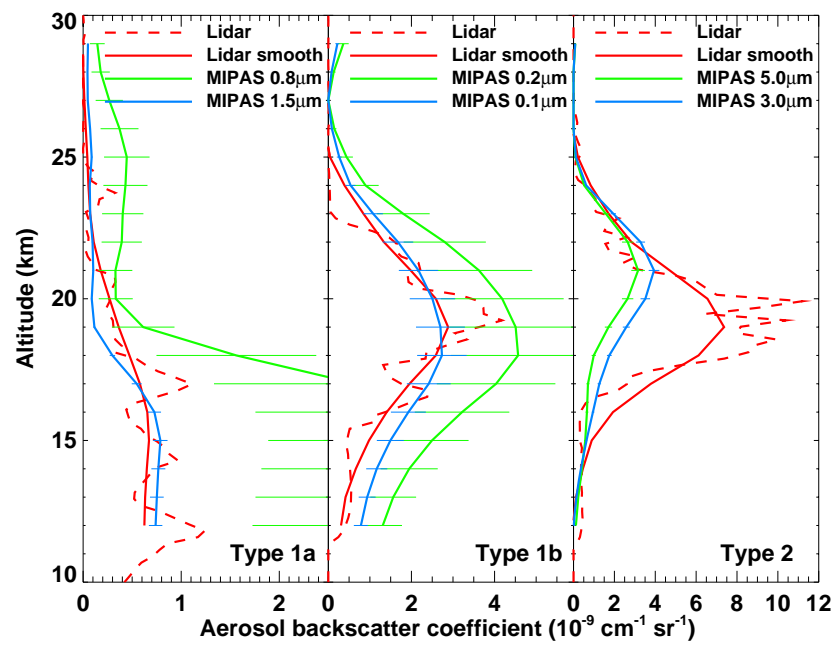

Fig. 8. Comparison of aerosol backscatter coefficients at $532 \mathrm{~nm}$ between Lidar measurements (red) and calculations based on MIPAS retrievals for two different median radii (green and blue). Solid red lines are the original Lidar observations, while dashed ones are convolved with the averaging kernel of the MIPAS results. Error bars indicate the variation of the results for the range of refractive indices for NAT (Type 1a), STS (Type 1b), and ice (Type 2) from literature.

efficients agree quite well. This strengthens the argument that the observations contain information there. Thus, it is possible to distinguish spectroscopically the PSC composition as shown in Fig. 6 for a tangent altitude of $23.4 \mathrm{~km}$.

\section{Comparison of PSC types between all MIPAS/Lidar collocations}

We now compare PSC Types observed by MIPAS and McMurdo Lidar during the Antarctic winter period 2003. In order to differentiate the PSC composition directly from MIPAS spectra in a time-efficient way, i.e. such that no explicit forward-model runs are necessary, we have applied the method which Spang and Remedios (2003) used to analyze PSC observations by CRISTA. This colour-ratio method discriminates measurements with the spectral band signature of NAT at $820 \mathrm{~cm}^{-1}$ by plotting the ratio of the radiances at around $820 \mathrm{~cm}^{-1}$ and $792 \mathrm{~cm}^{-1}$ versus the cloud index CI, i.e. the ratio of radiances at $792 \mathrm{~cm}^{-1}$ and $832 \mathrm{~cm}^{-1}$. The reason for selection of these spectral regions is as follows: at $832 \mathrm{~cm}^{-1}$ the trace gas interference is extremely low. Further, this wavenumber lies directly beside but is not influenced significantly by the sharp $820 \mathrm{~cm}^{-1}$ band of NAT. The $792 \mathrm{~cm}^{-1}$ wavelength region, which has a medium optical depth due to signatures of $\mathrm{CO}_{2}$, is used as a reference. Dividing the radiances at $792 \mathrm{~cm}^{-1}$ by those at $820 \mathrm{~cm}^{-1}$ reduces the temperature sensitivity of cloud detection from limb emission measurements. This method was used successfully for the first time for detection of clouds in CRISTA 
measurements (Spang et al., 2001a,b, 2002). It is also applied in the standard processing of MIPAS data (Spang et al., 2004). Thus, the CI as $\mathrm{x}$-axis of the colour-ratio plots is a measure for the presence of any cloud, independent of its composition: the smaller CI, the optically thicker the cloud. As y-axis we use the region of the NAT $v_{2}$ band-centre to separate NAT from no-NAT clouds. The resulting colour-ratios have been shown to provide a compact relationship when applied to PSC observations (Spang and Remedios, 2003).

The $820 \mathrm{~cm}^{-1}$ band appears to be particularly suited for detection of NAT from limb-spectra since it is spectrally sharp, it lies in close vicinity to the wavenumbers used for the cloud detection via the CI, and it is only weakly interfered by gas emission lines. Further, it lies at the longer-wavelength end of the MIPAS observation and, thus, is least affected by scattering effects. Other bands are partly or entirely covered by signatures of trace gases, too broad to be easily detected or stronger affected by scattering.

We have analysed this empirically derived colour-ratio method in a quantitative way by radiative transfer simulations. As a basis for these calculations we applied those refractive indices which resulted in the best agreement between MIPAS spectra and simulations in the broadband retrieval tests performed for the three typical Lidar cases as discussed in section 3.3: Biermann (1998)[coa] for NAT, Biermann et al. (2000) for STS, and Toon et al. (1994) for ice. We have used PSC volume densities for a variety of temperature profiles covering the range of variability in the Antarctic stratosphere, derived via equilibrium calculations and assuming different supersaturations. Further, various median particle radii were applied. The results are shown in Figure 9.

The plot is subdivided into regions of colour-ratios clearly related to one PSC composition and such which do not allow an unambiguous assignment. Region R1 contains only points from spectra calculated for $\beta$-NAT (red symbols). The solid black line (NAT detection line) separates the colourratios unambiguously related to NAT from the ambiguous ones. It was constructed as follows: a regression function of the type $1 /\left(a+b \times \mathrm{CI}+c \times \mathrm{CI}^{2}\right)$ has been fitted to the STS and ice radiance ratio distributions (open blue and green symbols in Fig. 9). This curve has been scaled by factor constant for all CI such that all points for NAT simulations with particles $\leq 2 \mu \mathrm{m}$ radius were still above the resulting curve $\left(1.13 /\left(0.164+0.884 \times \mathrm{CI}-0.065 \times \mathrm{CI}^{2}\right)\right)$. For larger particles, the $820 \mathrm{~cm}^{-1}$ signature flattens and, thus, it cannot be separated from STS or ice any more.

The R3 region, below the NAT detection line and left of the $\mathrm{CI}=1.3$ reference line, is dominated by simulated ice data points, and the R2 and R4 regions, below the NAT detection curve and right of the $\mathrm{CI}=1.3$ reference line contain simulated data points for all types of PSCs: STS, ice and large NAT particles with radii $>3 \mu \mathrm{m}$. Region $\mathrm{R} 2$ contains less than $5 \%$ simulated ice data points and the R3 region less than 5\% STS and no NAT. Thus, a measurement falling into the R1 region can be assigned to NAT, a measurement falling into R3 can

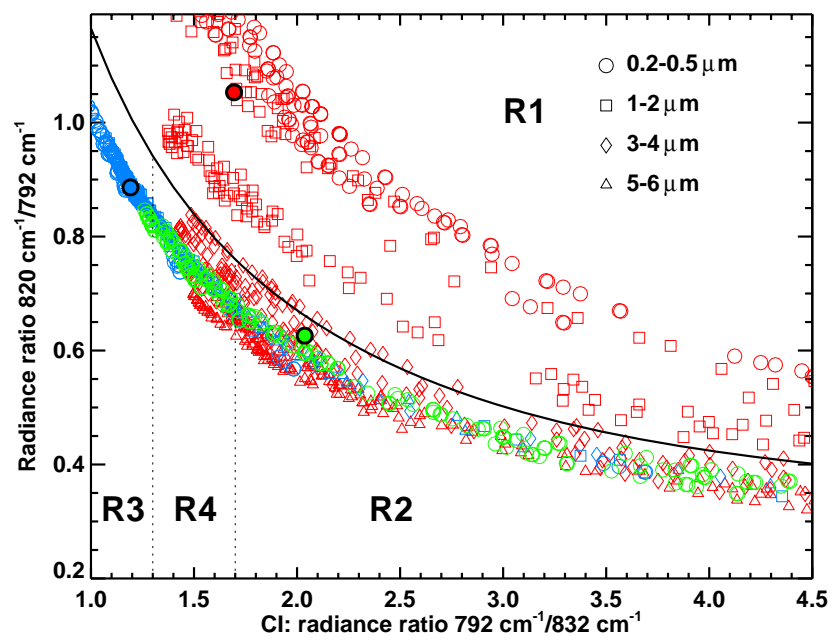

Fig. 9. Mean spectral intensity in the interval $819-821 \mathrm{~cm}^{-1}$ (I[819-821 $\left.\mathrm{cm}^{-1}\right]$ ) divided by I[788.2-796.25 $\left.\mathrm{cm}^{-1}\right]$ versus I[788.2-796.25 $\left.\mathrm{cm}^{-1}\right] /\left[\left[832.3-834.4 \mathrm{~cm}^{-1}\right]\right.$ from radiative transfer simulations based on a variety of particle compositions, sizes and number densities (see text). For the calculations the following refractive indices have been used. $\beta$-NAT (red), (Biermann, 1998)[coa]; STS (green) (Biermann et al., 2000); ice (blue) (Toon et al., 1994). The symbols denote the mean radii used for the underlying log-normal distributions (geometric standard deviation=1.35). The three data points enclosed by black circles are calculated from those measurements investigated in detail in Sect. 3.3: red: Type 1a, green: Type 1b, blue: Type 2 .

be ice or STS, and R2 and R3 measurements do not allow any clear assignment. In case of optically thick spectra, STS can be ruled out also for R3 measured data which implies unambiguous identification of ice.

The three test cases used for the detailed broadband simulations well represent the different colour-ratios of PSCs (solid bullets in Fig. 9).

The detection limit for PSCs from MIPAS has been set to $\mathrm{CI} \leq 4.5$ (Spang and Remedios, 2003). Our simulations show that this corresponds to a detection limit of PSCs with volume densities of $0.2-0.4 \mu \mathrm{m}^{3} \mathrm{~cm}^{-3}$. PSCs with volume densities of less than $0.2 \mu \mathrm{m}^{3} \mathrm{~cm}^{-3}$ are not detected while all PSCs with volume densities $>0.4 \mu \mathrm{m}^{3} \mathrm{~cm}^{-3}$ are detected.

For the comparison between MIPAS and Lidar PSC type determination we have selected MIPAS limb-scans closer than $\Delta t=8 \mathrm{~h}$ and $\Delta d=800 \mathrm{~km}$ to the Lidar measurements. This frequently results in multiple MIPAS matches per Lidar observation. We have ordered these matches for increasing values of $\Delta$ tot $[\mathrm{km}]=\Delta d[\mathrm{~km}]+100 \mathrm{~km} / \mathrm{h} \times|\Delta t|[\mathrm{h}]$. Figure 10 shows the comparison between the PSC-type altitude profiles from Lidar and MIPAS from mid-June until mid-September 2003. For MIPAS the results of the collocated limb-scans with smallest (MIPAS 1) and second smallest (MIPAS 2) $\Delta$ tot are given. Lidar PSC types have been derived by visual inspection of all backscatter and 


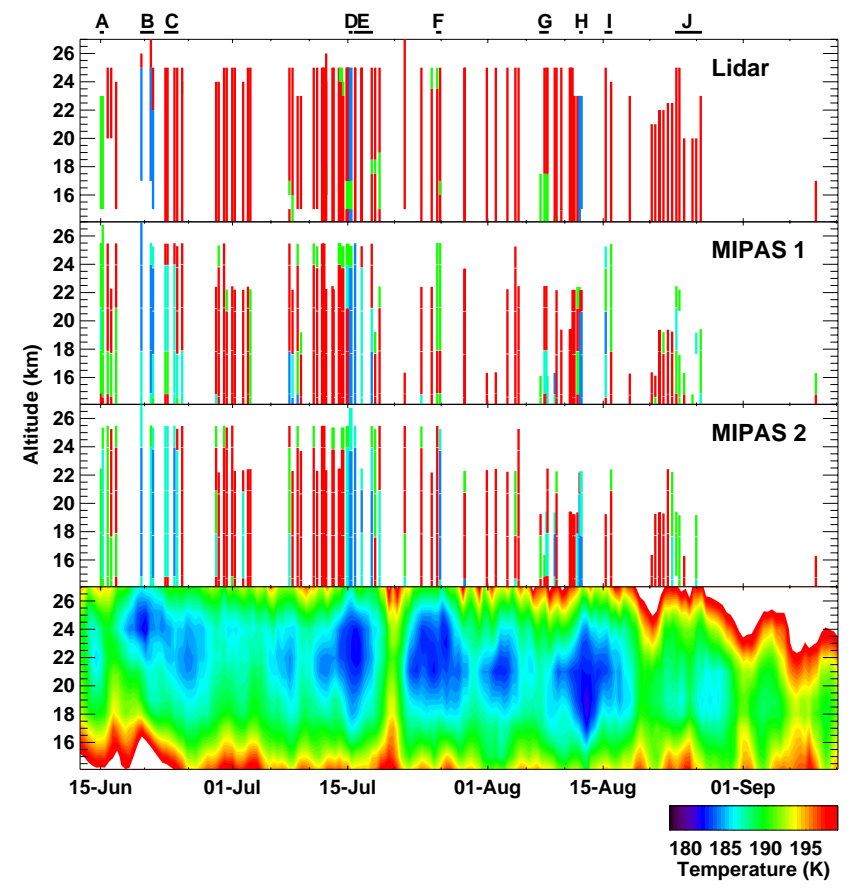

Fig. 10. Comparison between Lidar and MIPAS PSC type analysis. For Lidar, red indicates Type 1a, bright green Type $1 \mathrm{~b}$ and blue Type 2 PSC. In case of MIPAS red stands for R1, blue for R3, bright green for R2, and dark-green for region R4 in Fig. 9. "MIPAS 1" indicates the nearest and "MIPAS 2" the second nearest MIPAS limb-scan with respect to the Lidar observation in terms of $\Delta$ tot (see text). A-J denote periods discussed in the text. Temperatures are from ECMWF and have been corrected for an altitude dependent bias deduced from McMurdo sonde observations.

depolarization profiles and are identified by different colours. For MIPAS we have used the colour-ratio method and distinguished the different regions in Fig. 9 by different colours in Fig. 10.

The Lidar sequence indicates that Type 1a PSCs were the most frequent type of clouds above McMurdo during the winter. Pure Type $1 \mathrm{~b}$ clouds were only observed on 15 June (labelled A in Fig. 10). During few other days Type 1b signals were detected at distinct altitudes. Type 2 PSCs were present during three periods/days: 19-21 June (B), 15 July (D), and 12 August (H). These ice observations are well correlated with low temperatures over McMurdo (lower part of Fig. 10)

MIPAS-derived composition profiles match this general picture: mostly NAT was observed. On 15 June STS was seen, and ice was identified on all occasions when Lidar detected Type 2 clouds. Regarding cloud top height, both instruments agree quite well until the second half of July. Afterwards Lidar generally detected clouds higher up than MIPAS. This is due to the detection limit of MIPAS for clouds with low volume densities (see above). Such clouds which appear mainly in the second half of the winter can still be seen by Lidar. In the following, exceptions are discussed where Lidar-types do not match MIPAS-compositions.
On 23-24 June (C) Lidar observed Type 1a PSCs over McMurdo during three measurements while MIPAS saw NAT only above $24 \mathrm{~km}$. For the tangent altitudes below, there is indication for ice/STS/large NAT (region R4) and pure ice by MIPAS. Investigation of the related MIPAS spectra where ice is indicated (region R3) shows strong radiance signals typically for dense ice clouds. The surrounding MIPAS measurements on both days indicate, that McMurdo was located near a boundary with ice clouds towards the south and NAT in the north. Further, temperature over the station was still near the ice threshold. Thus, it is possible that MIPAS measurements were influenced by ice PSCs along its line-of-sight during this period.

On 16-18 July (E), differences between Lidar and MIPAS also appeared soon after a co-incident sighting of ice clouds (D). Thus, the situation was very similar to that on 23-24 June (C).

For one profile on 25-26 July (F) the colour ratio of the "closest" selected limb-scan "MIPAS 1", being $1.5 \mathrm{~h}$ and $100 \mathrm{~km}$ off McMurdo, belongs to R2 above about $18 \mathrm{~km}$. This indicates STS, but also assignment to large NAT particles or very thin ice layers is possible. However, Lidar detected STS only above $23 \mathrm{~km}$ and NAT below. The related "MIPAS 2" measurement $(\Delta t=0.1 \mathrm{~h}, \Delta d=600 \mathrm{~km})$, shows NAT. Further, in the second profile of "MIPAS 2" ice was detected, indicating that McMurdo was located in a zone of inhomogeneous PSC composition, thus complicating comparison of PSC-types between Lidar and MIPAS.

On 8 August (G), Lidar observed a Type 1b PSC from about 12 to $17.5 \mathrm{~km}$ altitude with a Type 1a cloud on top. Interestingly here MIPAS also detected NAT above a layer which falls, due to its relatively large optical depth, into R4 in the radiance-ratio plot, and thus, could wrongly be taken for an ice PSC.

On 15-16 August (I) Lidar detected Type 1a while we derived for "MIPAS 1" various compositions. Even signals as optically thick as ice were present. "MIPAS 2" is more in accordance with Lidar. We propose that the reason for this were inhomogeneous nacreous clouds caused by mountain wave activity which were observed near McMurdo during these days.

Such nacreous clouds may also be the reason for the enhanced radiances in MIPAS data on 24 and 26 August. In this period (J), however, the clouds were near the MIPAS detection limit which presumably lead to problems in determination of PSC composition.

Figure 11 shows the same coincident data between MIPAS and Lidar as in Fig. 10, but as scatterplot of color-ratios as derived from measured MIPAS spectra like the simulations in 9. The data points are color-coded on basis of the types derived from the coincident Lidar observations (Type 1a: red, Type 1b: green, Type 2: blue). Though there are not many Lidar observations of ice and STS compared to NAT, the plot is in general agreement with the simulations (Fig. 9): ice is mainly located in R3, STS in R2 and NAT in R1. Additionally only 


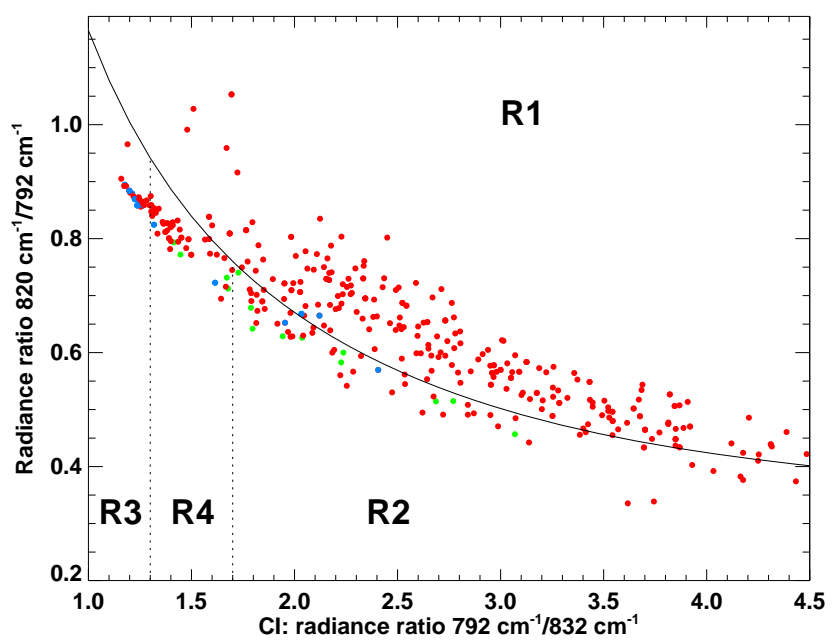

Fig. 11. Colour-ratio scatterplot for the Lidar-MIPAS coincident measurements in winter 2003. The plot contains one point per MIPAS measurement each for the nearest and second nearest MIPAS coincidences (in total 392 cases). Only those observations are shown where MIPAS and Lidar have detected PSCs. The colour scale of the plots indicates the types derived from the Lidar: red for Type 1a, green for Type 1b, and blue for Type 2 .

two ice-cases fall in R1 and the separation curve for R1 also follows rather well the ice and STS points. While most of the Lidar Type 1a PSCs lie in R1 some also fall in other regions, even in $\mathrm{R} 3$, which is not indicated by our simulations in Fig. 9. These cases have been discussed in context of Fig. 10 and are attributed to non-perfect co-incidences in sounded air-masses by MIPAS and Lidar, especially in the vicinity of large horizontal inhomogeneities.

\section{Search for NAD}

Due to its lower energy barrier for nucleation compared to NAT, NAD has been proposed as a possible component of Type 1a PSCs (Worsnop et al., 1993; Tabazadeh et al., 2001; Carslaw et al., 2002). We investigated whether there is spectroscopic evidence for NAD in MIPAS PSCs observations during the Antarctic winter of 2003.

Refractive indices (Fig. 1) and radiative transfer simulations for NAD (Fig. 4) show a prominent spectral signature at $810 \mathrm{~cm}^{-1}$ which is clearly distinguished from the NAT band at $820 \mathrm{~cm}^{-1}$. This difference between the location of the $v_{2}$ band of $\mathrm{NO}_{3}^{-}$of NAT and NAD is supported by various laboratory studies as summarized in Table 1.

We performed simulations of NAD spectra for various particle size distributions and plotted radiance ratios in the same manner as for the NAT detection (Fig. 12A). For these simulations the refractive indices of NAD by Niedziela et al. (1998) have been used because these were measured with a better spectral resolution $\left(2 \mathrm{~cm}^{-1}\right)$ than the data by Toon

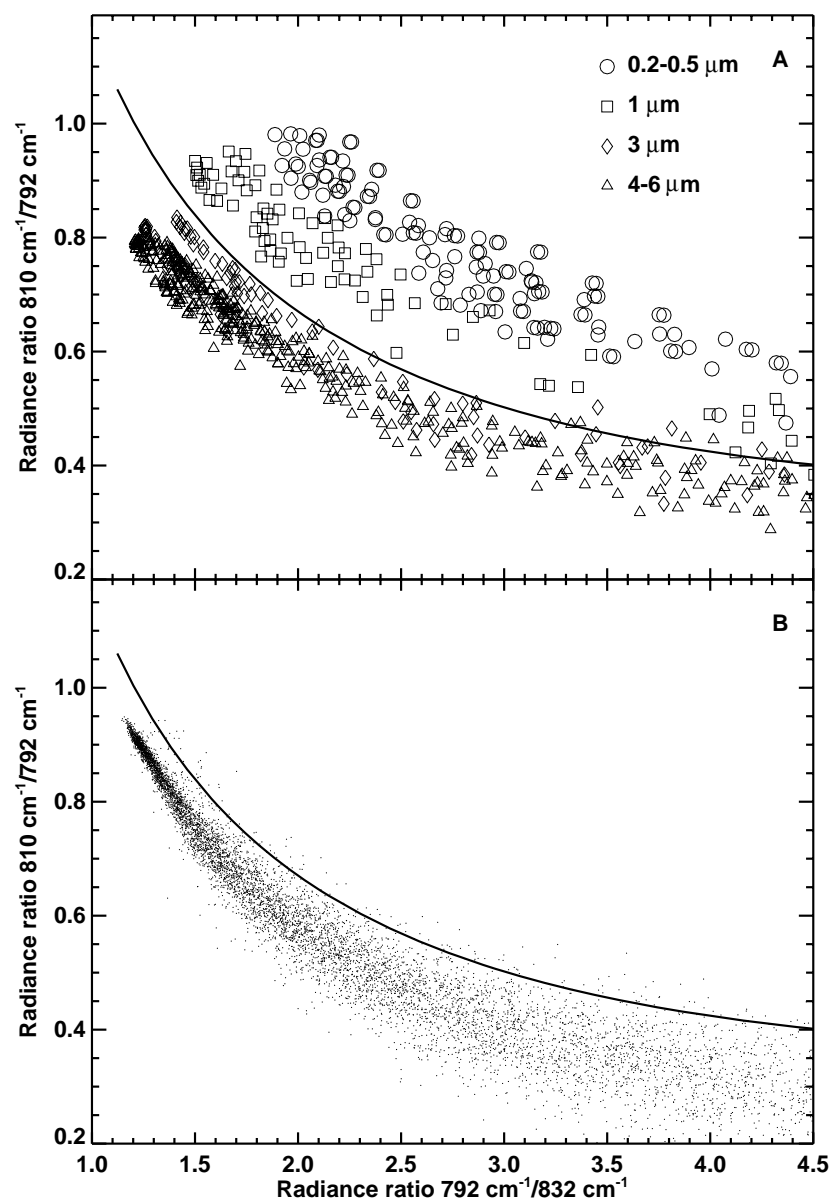

Fig. 12. Mean spectral intensity in the interval 810.05$810.35 \mathrm{~cm}^{-1}$ (I $\left.\left[810.05-810.35 \mathrm{~cm}^{-1}\right]\right)$ divided by I[788.2$\left.796.25 \mathrm{~cm}^{-1}\right]$ versus I[788.2-796.25 $\left.\mathrm{cm}^{-1}\right] /\left[\left[832.3-834.4 \mathrm{~cm}^{-1}\right]\right.$ of simulated (A) and measured (B) MIPAS PSC observations to search for NAD PSCs. The calculations in A are based on refractive index data of NAD by Niedziela et al. (1998) and a variety of particle number density profiles and particle sizes. Different symbols depict different median particle radii. B: all data points from MIPAS PSC observations for tangent altitudes between 16 and $25 \mathrm{~km}$ from May until October 2003.

et al. (1994) $\left(8 \mathrm{~cm}^{-1}\right)$ and, thus, probably represent better the sharp spectral feature.

The calculations in Fig. 12A show that it should be possible to detect NAD in MIPAS spectra for particle distributions with median radii up to about $1 \mu \mathrm{m}$. For larger particles the prominent feature at $810 \mathrm{~cm}^{-1}$ disappears. Comparison with the same plot derived from measurements (Fig. 12B) reveals no indication of a strong band of NAD in any MIPAS PSC spectra we have investigated. Only $1.8 \%$ of all 7641 PSC observations lie slightly above the separation curve. We could not identify any specific NAD signature through visual inspection of individual spectra either. From this observation and the MIPAS PSC detection limit discussed above we conclude that no PSCs consisting of NAD particles with radii 
smaller than about $1 \mu \mathrm{m}$ and volume densities larger than about $0.3 \mu \mathrm{m}^{3} \mathrm{~cm}^{-3}$ were present in the observed airmasses in the Antarctic stratosphere during 2003. It should be noted that this investigation is based on refractive indices of $\alpha$ NAD (see Sect. 3.1). Thus, we cannot judge about possible existence of $\beta$-NAD. However, also laboratory measurements of $\beta$-NAD (Grothe et al., 2004) show a sharp band at about $810 \mathrm{~cm}^{-1}$ (see Table 1). This indicates that the present analysis might be valid for both modifications of NAD.

\section{Summary and conclusions}

By detailed radiative transfer modelling we have demonstrated that a prominent spectral band at $820 \mathrm{~cm}^{-1}$ in MIPAS spectra of a PSC of Type 1a could best be modelled by the application of refractive index data of $\beta$-NAT derived from measurements by Biermann (1998). One of these two datasets, namely $\beta$-NAT[coa] resulted also in the best broadband fit between measurement and simulation. Despite not reproducing the $820 \mathrm{~cm}^{-1}$ feature, radiative transfer calculations using $\alpha$-NAT refractive indices deviate from the measurements mainly in the shorter wavelength channel. With indices of neither NAD, nor ice, nor STS it was possible to describe the observed band at $820 \mathrm{~cm}^{-1}$, nor has satisfactory broadband spectral agreement been obtained.

However, we cannot definitively decide which of the new datasets for $\beta$-NAT is more appropriate for the simulation of NAT observations in the mid-IR. On the one hand, $\beta$ NAT[coa] results in the best fit to the measured spectrum, especially in the region $1220-1490 \mathrm{~cm}^{-1}$. Further, this data is more similar to previous optical constants of $\beta$-NAT (Toon et al., 1994). On the other hand, the two datasets lead to different results for particle size ([coa] $0.8 \mu \mathrm{m}$ and [mol] $1.5 \mu \mathrm{m}$ median radius). We have shown that aerosol backscatter coefficients at $532 \mathrm{~nm}$ calculated on basis of MIPAS results for $r_{m}=1.5 \mu \mathrm{m}$ agree better with collocated Lidar observations. MIPAS spectra matching two Lidar examples of Type $1 \mathrm{~b}$ and Type 2 PSCs do not show the $820 \mathrm{~cm}^{-1}$. band and could well be simulated with refractive indices of STS and ice, respectively.

By simulations on basis of the new refractive indices we have analysed a colour-ratio method which had been derived empirically from CRISTA measurements to separate PSC types (Spang and Remedios, 2003). We have shown that NAT particles with radii smaller than about $3 \mu \mathrm{m}$ and volume densities larger than about $0.3 \mu \mathrm{m}^{3} \mathrm{~cm}^{-3}$ can be identified. Also dense ice clouds are easily distinguished while it is more difficult to differentiate between thinner ice clouds (e.g. not covering the entire field-of-view of MIPAS) and dense STS PSCs. The method has been applied to MIPAS measurements collocated with Lidar PSC observations from McMurdo. In general we found good agreement between PSC type identification from Lidar and the separation based on the MIPAS colour-ratio method. Differences are mainly attributed to temporal or spatial inhomogeneities of PSC-types and to the detection limit of MIPAS. Additionally, mixed-phase clouds pose potential problems to the detection scheme. We suppose that in general the type with the largest volume density over the field-of-view of MIPAS will be detected. A detailed analysis is envisaged in future.

The colour-ratio method has also been applied to search for the nitrate $\nu_{2}$ band of NAD located at about $810 \mathrm{~cm}^{-1}$, in MIPAS observations. We have not found any definite evidence and conclude that very likely no NAD PSCs with median particle radii of less than $1 \mu \mathrm{m}$, volume densities larger than about $0.3 \mu \mathrm{m}^{3} \mathrm{~cm}^{-3}$, and exhibiting the $810 \mathrm{~cm}^{-1}$ band existed over Antarctica in 2003.

The conclusions above are drawn on basis of available optical constants of possible PSC compositions. It has to be noted that IR laboratory measurements can be affected e.g. by the orientation (Koch et al., 1996; Mate et al., 1996), the thickness (Fernández-Torre et al., 2005), or the composition (Delval and Rossi, 2005; Tizek et al., 2004) of the sample leading to differences in the obtained spectra. An effect on band position due to particle shape was shown by Wagner et al. (2005). This analysis revealed a shift to lower wavenumbers of major $\alpha$-NAD absorption bands with increasing deviation from spherical shape. However, estimates for the $\alpha$-NAD band at $810 \mathrm{~cm}^{-1}$ point to very weak shifts towards smaller wavenumbers (R. Wagner, personal communication). Thus, it is unlikely that in atmospheric observations the $810 \mathrm{~cm}^{-1}$ band of NAD can be shifted to $820 \mathrm{~cm}^{-1}$ and be mistaken with the NAT band there. The spectral location of the distinct $820 \mathrm{~cm}^{-1}$ band observed by MIPAS which we attribute to NAT appears to be quite reproducible and distinct from the location of NAD in the laboratory (see Table 1).

The present work is the basis for an analysis of the evolution of PSC-types during the onset of PSC activity in the Antarctic polar vortex in May and June 2003 which is reported in a companion paper (Höpfner et al., 2006).

\section{Appendix A Experimental}

The experimental procedure used by Biermann (1998) to obtain IR spectra of $\beta$-NAT is described in the following.

Figure 13 shows a schematic drawing of the lowtemperature FTIR absorption reflection cell. The infrared light with wavelengths of 2-20 $\mu \mathrm{m}$ from a globar source enters the cell through a $\mathrm{KBr}$-window. At the surface of a polished gold mirror (diameter $=30 \mathrm{~mm}$, reflectivity $=98 \%$ ) the beam $($ diameter $=15 \mathrm{~mm})$ is reflected back into the spectrometer. The gold surface, which has been vapour deposited on a copper block, is cooled by thermal contact with a liquid nitrogen-filled cryostat and resistively heated to a desired temperature (130-300 K) regulated by a Conductus LTC-10 controller (stability $\pm 0.001 \mathrm{~K}$ ). The temperature is measured by a PT-100 resistor about $1 \mathrm{~mm}$ below the centre of the gold surface and recorded via a IEEE card. The consistency of the 


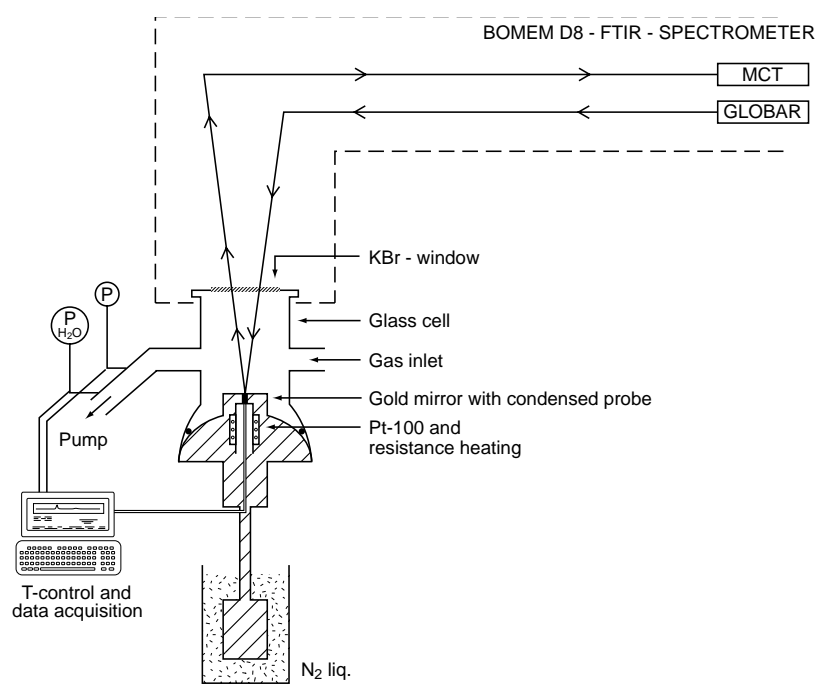

Fig. 13. Experimental set-up for FTIR spectroscopic measurements of stratospheric condensates in contact with the gas-phase.

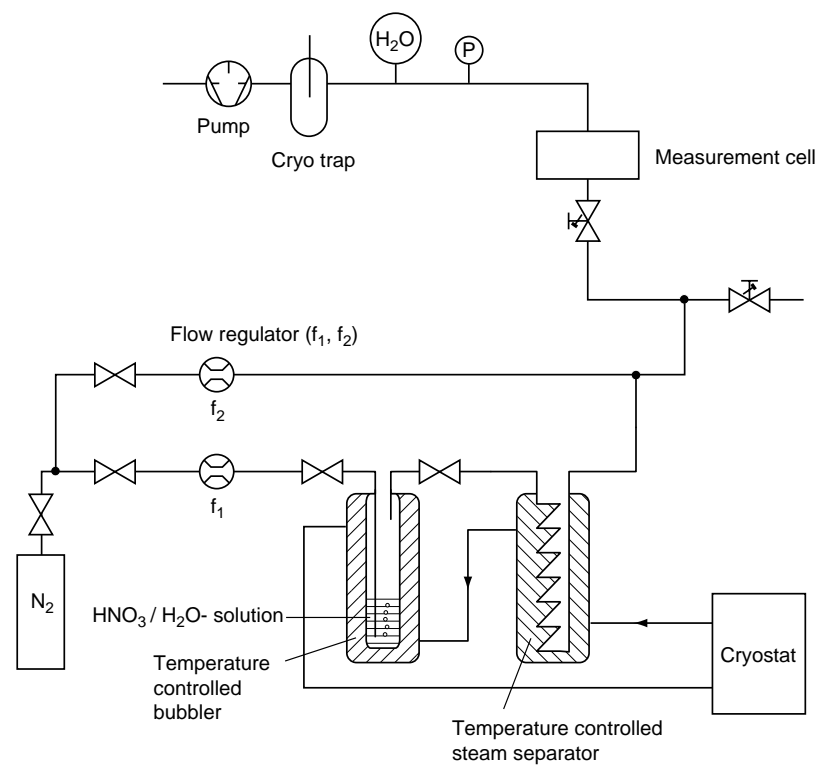

Fig. 14. Set-up to obtain gas phases with stratospheric mixing ratios.

temperature at the gold surface and the PT-100 temperature has been tested by observation of the infrared spectrum of a well defined phase transition of cyclohexane which occurs at $189.06 \mathrm{~K}$ (Aston et al., 1943). The measured temperature of the phase transition agrees within $0.005 \mathrm{~K}$ with the value from literature. Further, ice-frostpoint calibrations have been performed during the measurements (see below).

Around the copper-block below the gold-surface a ringshaped barrier of stainless steel is attached such that all parts outside the gold-mirror are warmer than the surface observed by the spectrometer. Inside the ring the temperature gradient

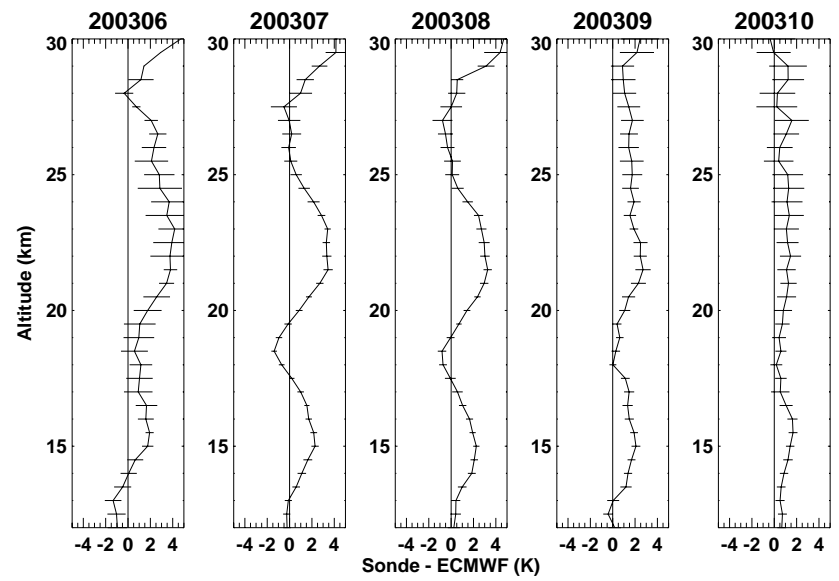

Fig. 15. Monthly mean differences between temperatures from ozone-sondes launched at McMurdo and ECMWF analysis for June-October 2003. Error bars represent the 1- $\sigma$ error of the mean profile. Profile parts with missing error bars indicate only one available sonde profile at the related altitudes. Number of sonde profiles per month: June: 4, July: 11, August: 14, September: 13, October: 12.

is assumed to be small due to the high thermal conductivity of the copper. This assumption is supported by observations during the ice-frostpoint calibration: at the moment when the spectrometer detected no ice any more, also by visible inspection no ice has been present at any part of the surface. Thus, the spectrometer definitely sampled the coldest part of the surface. The measurement cell (volume $=100 \mathrm{~cm}^{3}$ ) is made of glass and has three inlets and outlets for gas. Even at gold surface temperatures of $150 \mathrm{~K}$ the outside temperature of the glass cell has been higher than the condensation temperature of air outside the cell.

The gas phase inside the cell is produced by the setup shown schematically in Fig. 14. Its central element is a temperature controlled glass container filled with binary $\mathrm{H}_{2} \mathrm{O} / \mathrm{HNO}_{3}$ solution. The flux $\left(f_{1}\right)$ of the inert gas $\mathrm{N}_{2}(5.0)$ through the binary solution is regulated by a tylan mass flow controller. The gas phase concentration inside the bubbles in thermodynamic equilibrium is determined by the concentration and temperature of the binary solution. To remove possible supersaturation due to entrainment of droplets from the solution, the gas subsequently flows through a separator at the same temperature as the bubbler. The gas is then further diluted by a second flow controller $\left(f_{2}\right)$ and enters the measurement cell through a temperature controlled Teflonglass valve. The gas leaves the cell pumped by a rotary vane pump (Balzers) via a lq. $\mathrm{N}_{2}$ cryo trap. The absolute pressure is measured directly behind the cell (Baratron, measurement range $0-1$ Torr $\pm 1 \times 10^{-5}$ Torr) and adjusted to a value of about $0.85 \mathrm{hPa}$ by the needle valve at the inlet. Relative humidity is monitored with a dew point sensor (Panametrics, relative error $\pm 3 \mathrm{~K}$ ). The gas-phase composition in 
the cell can be adjusted over a broad range by variation of the composition of the binary solution, the temperature of the bubbler and the mixing ratios of the two inert gas flows $f_{1}$ and $f_{2}$. The range of possible flows $f_{1}=5-45 \mathrm{sccm}$ and $f_{2}=50-450 \mathrm{sccm}$ combined with the range of the bubbler temperature lead to partial pressures of $5 \times 10^{-5} \leq$

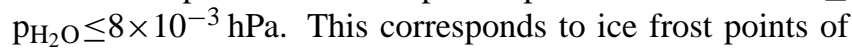
$180-211 \mathrm{~K}$ in the cell. Through variation of the composition of the binary $\mathrm{H}_{2} \mathrm{O} / \mathrm{HNO}_{3}$ solution in the bubbler $\mathrm{HNO}_{3}: \mathrm{H}_{2}$

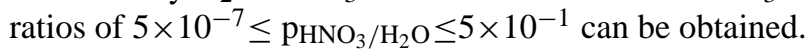

Before each spectroscopic observation, a reference spectrum has been recorded. It has been verified that the reference spectra are temperature-independent within the temperature range of the measurements. During the measurements, ice or a co-condensate of ice and $\mathrm{HNO}_{3}$ forms at the gold surface when the temperature is colder than a critical temperature. The light intensity $I(v)$ reaching the detector is $I(v)=I_{0}(v)(1-R(v)) \exp (-\alpha(v) x)$ where $v$ is the wavenumber of the light, $R(v)$ the reflectivity and $\alpha(v)$ the absorption coefficient of the sample. Further, $I_{0}(v)$ is the reference spectrum and $x$ the length of the light-path through the sample. In this formula the intensity of surface reflected light reaching the detector is assumed to be negligible due to the polycrystalline samples in this experiment.

Frost point calibrations have been performed to test the water vapour partial pressures from the gas-mixing set-up and the temperature of the condensed sample. After a conditioning phase of 3-4 h of constant water vapour gas-flow through the cell, the gold surface has been cooled down to $160 \mathrm{~K}$ with a cooling rate of $15 \mathrm{~K} / \mathrm{min}$ leading to ice supersaturation of more than $20 \mathrm{~K}$ and formation of a uniform polycrystalline ice film. After typically $5 \mathrm{~min}$, when a few monolayers thick ice film visible in the IR spectrum had formed, the temperature has been raised to about $5 \mathrm{~K}$ below the calculated frost point (Janscso et al., 1970). After a layer of about $0.5 \mu \mathrm{m}$ ice had formed, it has been warmed up in steps of $0.5 \mathrm{~K}$ with delays of at least $5 \mathrm{~min}$ for setting up equilibrium. The frost point is characterized by recording time-invariant ice spectra being recorded which evaporate during further warm-up. The consistency between adjusted and measured gas phase concentration has been better than $5 \%$ (or $0.3 \mathrm{~K}$ temperature difference) in case of pure $\mathrm{H}_{2} \mathrm{O}$ gas phase and better than $10 \%$ (or $0.6 \mathrm{~K}$ temperature difference) for binary $\mathrm{H}_{2} \mathrm{O} / \mathrm{HNO}_{3}$ gas phases.

The NAT existence temperature depends on both, the $\mathrm{H}_{2} \mathrm{O}$ and the $\mathrm{HNO}_{3}$ partial pressure (Hanson and Mauersberger, 1988). It has been measured in the same manner as the ice frost point by observation of time-constant infrared NAT spectra. The difference between measured and theoretical value has always been less than $0.5 \mathrm{~K}$.

To compare spectra of ice-doped NAT with pure NAT crystals measurements have been made with samples crystallized from solutions of $53.8 \mathrm{wt} \% \mathrm{HNO}_{3}\left(1: 3 \mathrm{HNO}_{3}: \mathrm{H}_{2} \mathrm{O}\right)$, $50 \mathrm{wt} \% \mathrm{HNO}_{3}\left(1: 3.4 \mathrm{HNO}_{3}: \mathrm{H}_{2} \mathrm{O}\right)$, and $45 \mathrm{wt} \% \mathrm{HNO}_{3}(1: 4.2$ $\mathrm{HNO}_{3}: \mathrm{H}_{2} \mathrm{O}$ ) using the low-temperature transmission cell as described in Biermann (1998) and Biermann et al. (2000) (for the obtained spectra see Fig. 4.11 on page 64 in Biermann (1998)). The splitting of the OH-band at $3220 \mathrm{~cm}^{-1}$ is more pronounced the more ice can be formed beside NAT. The interpretation that the splitting of the band is due to presence of ice is supported by spectra obtained of a frozen $45 \mathrm{wt} \% \mathrm{HNO}_{3}$ solution at temperatures above and below the NAT/ice eutectic. As long as ice is thermodynamically stable $(\mathrm{T} \leq 230 \mathrm{~K})$ the splitting is pronounced. Above the NAT/ice eutectic, however, the splitting is blurred and the spectrum equals the one of a crystallized $1: 3 \mathrm{HNO}_{3}: \mathrm{H}_{2} \mathrm{O}$ solution (see Fig. 4.12 on page 64 in Biermann (1998)). The spectrum obtained from crystallization of the $1: 3 \mathrm{HNO}_{3}: \mathrm{H}_{2} \mathrm{O}$ solution has been used to derive the refractive indices termed $\beta$ NAT[mol] as described in Sect. 3.1.

The second data set of optical constants ( $\beta$-NAT[coa]) has been derived from measurements using the absorption reflection cell described in this appendix. In this experiment, after formation of a thin film at $160 \mathrm{~K}$, NAT has been cocondensed with ice from gas-phase with a $\mathrm{HNO}_{3}: \mathrm{H}_{2} \mathrm{O}$ mixing ratio of $1: 15$ at $195 \mathrm{~K}$ which is about $5 \mathrm{~K}$ below the ice frost point. Upon heating, the ice evaporates at about $200 \mathrm{~K}$ and a NAT layer is deposited as long as the actual temperature is below the NAT existence temperature of $211 \mathrm{~K}$.

The absorption coefficient $\alpha$ is directly connected with the imaginary part $k(v)$ of the complex refractive index $n(v)+i k(v)$ by $\alpha(v)=4 \pi k(v) v$. For the determination of $k(v)$ from the measured spectra $I(v)$ and the reference spectra $I_{0}(v)$ the formula $I(v)=I_{0}(v) \exp (-\alpha(v) x)$ has been used. Thus, to derive $k(v)$ it is necessary to determine the path length $x$. This has been performed by fitting the measurements to the spectrum of $\beta$-NAT from the work of Toon et al. (1994). The total error of $x$ and, thus, also of $k(v)$ is estimated to $30 \%$. The mainly contributing sources are (1) the uncertainty of the optical constants: 10-20\% (Toon et al., 1994), (2) the neglect of reflection losses: 6\%, and (3) intensity fluctuations of the light source and non-linear effects of the detector: $10 \%$.

\section{Appendix B Antarctic 2003 ECMWF temperature bias}

We compared ECMWF temperature analyses data $\left(\mathrm{T}_{106}\right.$, source: NADIR (NILU's Atmospheric Database for Interactive Retrieval)) with temperatures from ozone sondes launched at McMurdo from June until October 2003. Figure 15 shows the resulting mean difference profiles for each month. These profiles were obtained by linear interpolation of sonde and ECMWF data to a $0.5 \mathrm{~km}$ altitude grid. The comparison shows that ECMWF has a significant cold bias between 13 and $17 \mathrm{~km}$ of up to $2 \mathrm{~K}$ and between 20 and $25 \mathrm{~km}$ up to $3.5 \mathrm{~K}$. The bias is largest during the mid-winter, while in September and October it decreases. This might point to some error due to PSCs in the satellite data used by the ECMWF assimilation scheme. Such temperature differences 
in the Antarctic polar winter region 2003 have also been reported from CHAMP radio occultation data (Gobiet et al., 2005).

Acknowledgements. Authors of this work were supported by the German HGF-Vernetzungsfonds ENVISAT (BMBF 01SF9953/8). MIPAS spectra were provided by the European Space Agency and meteorological data by ECMWF via NILU. Lidar measurements were supported by the Italian Programma Nazionale di Ricerche in Antartide. Gratitude is extended to the US National Science Foundation for making McMurdo Station available for the Lidar measurements and for supplying winter-over science technical support. Related to this, we especially thank T. Deshler for his support. We thank the Network for the Detection of Stratospheric Change (NDSC) database for access to McMurdo sonde data and P. von der Gathen for indicating temperature biases of ECMWF analyses. We thank Hinrich Grothe and two anonymous referees for helpful comments.

Edited by: U. Pöschl

\section{References}

Adriani, A., Deshler, T., Gobbi, G. P., Johnson, B. J., and Di Donfrancesco, G.: Polar stratospheric clouds over McMurdo, Antarctica, during the 1991 spring: Lidar and particle counter measurements, Geophys. Res. Lett., 19, 1755-1758, 1992.

Adriani, A., Massoli, P., Di Donfrancesco, G., Cairo, F., Moriconi, M. L., and Snels, M.: Climatology of polar stratospheric clouds based on lidar observations from 1993 to 2001 over McMurdo Station, Antarctica, J. Geophys. Res., 109(D24), D24 211, doi:10.1029/2004JD004800, 2004.

Aston, J. G., Szasa, G. J., and Fink, H.L.: The heat capacity and entropy, heats of transition, fusion and vaporization and the vapor pressures of cyclohexane. The vibrational frequencies of alicyclic ring systems, J. Am. Chem. Soc., 65, 1135-1139, 1943.

Arnold, F., Schlager, H., Hoffmann, J., Metzinger, P., and Spreng, S.: Evidence for stratospheric nitric acid condensation from balloon and rocket measurements in the Arctic, Nature, 342, 493497, 1989.

Biermann, U. M.: Gefrier- und FTIR-Experimente zur Nukleation und Lebensdauer stratosphärischer Wolken, Ph.D. thesis, Universität Bielefeld, cuvillier Verlag, ISBN 3-89712-212-X, 1998.

Biermann, U. M., Luo, B. P., and Peter, T.: Absorption spectra and optical constants of binary and ternary solutions of $\mathrm{H}_{2} \mathrm{SO}_{4}$, $\mathrm{HNO}_{3}$, and $\mathrm{H}_{2} \mathrm{O}$ in the mid infrared at atmospheric temperatures, J. Phys. Chem. (A), 104, 783-793, 2000.

Browell, E. V., Butler, C. F., Ismail, S., Robinette, P. A., Carter, A. F., Higdon, N. S., Toon, O. B., Schoeberl, M. R., and Tuck, A. F.: Airborne lidar observations in the wintertime Arctic stratosphere: polar stratospheric clouds, Geophys. Res. Lett., 17, 385388, 1990.

Carslaw, K. S., Luo, B. P., Clegg, S. L., Peter, T., Primblecombe, P., and Crutzen, P. J.: Stratospheric aerosol growth and $\mathrm{HNO}_{3}$ gas phase depletion from coupled $\mathrm{HNO}_{3}$ and water uptake by liquid particles, Geophys. Res. Lett., 21, 2479-2482, 1994.

Carslaw, K. S., Luo, B., and Peter, T.: An analytic expression for the composition of aqueous $\mathrm{HNO}_{3}-\mathrm{H}_{2} \mathrm{SO}_{4}$ stratospheric aerosols including gas phase removal of $\mathrm{HNO}_{3}$, Geophys. Res. Lett., 22, 1877-1880, 1995.

Carslaw, K. S., Kettleborough, J. A., Northway, M. J., Davies, S., Gao, R., Fahey, D. W., Baumgardner, D. G., Chipperfield, M. P., and Kleinböhl, A.: A vortex-scale simulation of the growth and sedimentation of large nitric acid hydrate particles, J. Geophys. Res., 107(D20), SOL 43-1, 8300, doi:10.1029/2001JD000467, 2002.

Delval, D. and Rossi, M.: Influence of monolayer amounts of $\mathrm{HNO}_{3}$ on the evaporation rate of $\mathrm{H}_{2} \mathrm{O}$ over ice in the range 179 to $208 \mathrm{~K}$ : A quartz crystal microbalance study, J. Phys. Chem. A, 109, 7151-7165, 2005.

Deshler, T., Nardi, B., Adriani, A., Cairo, F., Hansen, G., Fierli, F., Hauchecorne, A., and Pulvirenti, L.: Determining the index of refraction of polar stratospheric clouds above Andoya $\left(69^{\circ} \mathrm{N}\right)$ by combining size-resolved concentration and optical scattering measurements, J. Geophys. Res., 105, 3943-3954, 2000.

Echle, G., von Clarmann, T., and Oelhaf, H.: Optical and microphysical parameters of the Mt. Pinatubo aerosol as determined from MIPAS-B mid-IR limb emission spectra, J. Geophys. Res., 103, 19 193-19211, 1998.

ESA: Envisat MIPAS: An instrument for atmospheric chemistry and climate research, Tech. Rep. SP-1229, European Space Agency, SA Publications Division, ESTEC, P. O. Box 299, 2200 AG Noordwijk, The Netherlands, 2000.

Fahey, D. W., Murphy, D. M., Kelly, K. K., Ko, M. K. W., Proffitt, M. H., Eubank, C. S., Ferry, G. V., Loewenstein, M., and Chan, K. R.: Measurements of Nitric Oxide and Total Reactive Nitrogen in the Antarctic Stratosphere: Observations and Chemical Implications, J. Geophys. Res., 94, 16 665-16 681, 1989.

Fernández-Torre, D., Escribano, R., Herrero, V. J., Maté, B., Moreno, M. A., and Ortega, I. K.: Theoretical Calculations of Refractive Indices and Optical Effects in Spectra of Nitric Acid and Nitric Acid Monohydrate Crystals, J. Phys. Chem. B, 109, 18 010-18 017, 2005.

Fischer, H. and Oelhaf, H.: Remote sensing of vertical profiles of atmospheric trace constituents with MIPAS limb-emission spectrometers, Appl. Opt., 35, 2787-2796, 1996.

Gobiet, A., Foelsche, U., Steiner, A. K., Borsche, M., Kirchengast, G., and Wickert, J.: Climatological validation of stratospheric temperatures in ECMWF operational analyses with CHAMP radio occultation data, Geophys. Res. Lett., 32(12), L12806, doi:10.1029/2005GL022617, 2005.

Grothe, H., Lund Myhre, C. E., and Tizek, H.: Vibrational spectra of nitric acid dihydrate (NAD). Vibr. Spectrosc., 34, 55-62, 2004.

Hanson, D. and Mauersberger, K.: Laboratory studies of the nitric acid trihydrate: Implications for the south polar stratosphere, Geophys. Res. Lett., 15, 855-858, 1988.

Höpfner, M., Blom, C. E., Fischer, H., Glatthor, N., Gulde, T., W., Piesch, C., Renger, W., and Wirth, M.: $\mathrm{HNO}_{3}$ and PSC Measurements from the TRANSALL: Sequestering of $\mathrm{HNO}_{3}$ in the Winter of 1994/95, J. Atmos. Chem., 30, 61-79, 1998.

Höpfner, M.: Study on the impact of polar stratospheric clouds on high resolution mid-IR limb emission spectra, J. Quant. Spectrosc. Radiat. Transfer, 83, 93-107, 2004.

Höpfner, M. and Emde, C.: Comparison of single and multiple scattering approaches for the simulation of limb-emission observations in the mid-IR, J. Quant. Spectrosc. Radiat. Transfer, 91, 275-285, 2004. 
Höpfner, M., Oelhaf, H., Wetzel, G., Friedl-Vallon, F., Kleinert, A., Lengel, A., Maucher, G., Nordmeyer, H., Glatthor, N., Stiller, G. P., von Clarmann, T., Fischer, H., Kröger, C., and Deshler, T.: Evidence of scattering of tropospheric radiation by PSCs in mid-IR limb emission spectra: MIPAS-B observations and KOPRA simulations, Geophys. Res. Lett., 29(8), 119-1, 1278, doi:10.1029/2001GL014443, 2002.

Höpfner, M., von Clarmann, T., Fischer, H., Glatthor, N., Grabowski, U., Kellmann, S., Kiefer, M., Linden, A., Tsidu, G. M., Milz, M., Steck, T., Stiller, G. P., and Wang, D.-Y.: Determination of PSC properties from MIPAS/ENVISAT limb emission measurements during the Antarctic winter 2003, in OZONE, Proceedings of the XX Quadrennial Ozone Symposium, edited by: Zerefos, C. S., International Ozone Commission, Athens, Greece, 974-975, 2004.

Höpfner, M., Larsen, N., Spang, R., Luo, B. P., Ma, J., Svendsen, S. H., Eckermann, S. D., Knudsen, B., Massoli, P., Cairo, F., Stiller, G., v. Clarmann, T., and Fischer, H.: MIPAS detects Antarctic stratospheric belt of NAT PSCs caused by mountain waves, Atmos. Chem. Phys., 6, 1221-1230, 2006.

Hudson, P. K., Zondlo, M. A, and Tolbert, M. A.: The interaction of methanol, acetone, and acetaldehyde with ice and nitric aciddoped ice: implications for cirrus clouds, J. Phys. Chem. (A), 106, 2882-2888, 2002.

Jansco, G., Pupezin, J., and Van Hook, W. A.: The vapor pressure of ice between $+10^{-2}$ and $-10^{+2}{ }^{\circ} \mathrm{C}$, J. Phys. Chem., 74, 2984 2989, 1970.

Koch, T. G., Holmes, N. S., Roddis, T. B., and Sodeau, J. R.: Lowtemperature reflection/absorption IR study of thin films of nitric acid hydrates and ammonium nitrate adsorbed on gold foil, J. Chem. Soc., Faraday Trans., 92, 4787-4792, 1996.

Koehler, B. G., Middlebrook, A. M., and Tolbert, M. A.: Characterization of model polar stratospheric cloud films using Fourier transform infrared spectroscopy and temperature programmed desorption, J. Geophys. Res., 97, 8065-8074, 1992.

Larsen, N., Mikkelsen, I., Knudsen, B. M., Schreiner, J., Voigt, C., Mauersberger, K., Rosen, J. M., and Kjome, N. T.: Comparison of chemical and optical in situ measurements of polar stratospheric cloud particles, J. Geophys. Res., 105, 1491-1502, 2000.

Lebrun,N. , Mahe, F., Lamiot, J., Foulon, M., and Petit, J. C.: A new crystalline phase of nitric acid dihydrate, Acta Cryst., C57, 1129-1131, 2001.

Lund Myhre, C. E., Grothe, H., Gola, A. A., and Nielsen, C. J.: Optical constants of $\mathrm{HNO}_{3} / \mathrm{H}_{2} \mathrm{O}$ and $\mathrm{H}_{2} \mathrm{SO}_{4} / \mathrm{HNO}_{3} / \mathrm{H}_{2} \mathrm{O}$ at low temperatures in the infrared region, J. Phys. Chem. A, 109, 71667171, 2005.

Luo, B., Krieger, U. K., and Peter, T.: Densities and refractive indices of $\mathrm{H}_{2} \mathrm{SO}_{4} / \mathrm{HNO}_{3} / \mathrm{H}_{2} \mathrm{O}$ solutions to stratospheric temperatures, Geophys. Res. Lett., 23, 3707-3710, 1996.

Mate, B., Ortega, I. K., Moreno, M. A., Escribano, R., and Herrero, V. J.: Investigation of orientation effects in films of nitric acid trihydrate, Phys. Chem. Chem. Phys., 6, 4047-4055, 2004.

McCormick, M. P.: High-latitude stratospheric aerosol measured by the SAM II satellite system in 1978 and 1979, Science, 214, 328-331, 1981 .

Middlebrook, A. M., Berland, B. S., George, S. M., Tolbert, M. A., and Toon, O. B.: Real refractive indices of infrared-characterized nitric-acid/ice films: Implications for optical measurements of polar stratospheric clouds, J. Geophys. Res., 99, 25 655-25 666,
1994.

Minogue, N., Riordan, E., and Sodeau, J. R., Raman Spectroscopy as a Probe of Low-Temperature Ionic Speciation in Nitric and Sulfuric Acid Stratospheric Mimic Systems, J. Phys. Chem. A, 107, 4436-4444, 2003

Niedziela, R. F., Miller, R. E., and Worsnop, D. R.: Temperatureand frequency-dependent optical constants for nitric acid dihydrate from aerosol spectroscopy, J. Phys. Chem. (A), 102, 64776484, 1998.

Niedziela, R. F., Norman, M. L., DeForest, C. L., Miller, R. E., and Worsnop, D. R.: A Temperature- and Composition-Dependent Study of $\mathrm{H}_{2} \mathrm{SO}_{4}$ Aerosol Optical Constants Using Fourier Transform and Tunable Diode Laser Infrared Spectroscopy, J. Phys. Chem. (A), 103, 8030-8040, 1999.

Norman, M. L., Qian, J., Miller, R. E., and Worsnop, D.: Infrared complex refractive indices of supercooled liquid $\mathrm{HNO}_{3} / \mathrm{H}_{2} \mathrm{O}$ aerosols, J. Geophys. Res., 104, 30 571-30 584, 1999.

Norman, M. L., Miller, R. E., and Worsnop, D.: Ternary $\mathrm{H}_{2} \mathrm{SO}_{4} / \mathrm{HNO}_{3} / \mathrm{H}_{2} \mathrm{O}$ Optical Constants: New Measurements from Aerosol Spectroscopy under Stratospheric Conditions, J. Phys. Chem. (A), 106, 6075-6083, 2002.

Poole, L. R. and McCormick, M. P.: Airborne lidar observations of Arctic polar stratospheric clouds: Indications of two distinct growth stages, Geophys. Res. Lett., 15, 21-23, 1988.

Poole, L. R., Trepte, C. R., Harvey, V. L., Toon, G. C., and VanValkenburg, R. L.: SAGE III observations of Arctic polar stratospheric clouds - December 2002, Geophys. Res. Lett., 30(23), A11, 2216, doi:10.1029/2003GL018496, 2003.

Richwine, L. J., Clapp, M. L., Miller, R. E., and Worsnop, D. R.: Complex refractive indices in the infrared of nitric acid trihydrate aerosols, Geophys. Res. Lett., 22, 2625-2628, 1995.

Ritzhaupt, G. and Devlin, J. P.: Infrared spectra of nitric and hydrochloric acid hydrate thin films, J. Phys. Chem., 95, 90-95, 1991.

Rodgers, C. D.: Inverse Methods for Atmospheric Sounding: Theory and Practice, vol. 2 of Series on Atmospheric, Oceanic and Planetary Physics, edited by: Taylor, F. W., World Scientific, 2000.

Santee, M. L., Tabazadeh. A., Manney, G. L., Salawitch, R. J., Froidevaux, L., Read, W.G., and Waters, J. W.: UARS Microwave Limb Sounder $\mathrm{HNO}_{3}$ observations: Implications for Antarctic polar stratospheric clouds, J. Geophys. Res., 103, 13,285-13,313, 1998.

Scarchilli, C., Adriani, A., Cairo, F., Donfrancesco, G. D., Buontempo, C., Snels, M., Moriconi, M. L., Deshler, T., Larsen, N., Luo, B., Mauersberger, K., Ovarlez, J., Rosen, J., and Schreiner, J.: Determination of polar stratospheric cloud particle refractive indices by use of in situ optical measurements and T-matrix calculations, Appl. Opt., 44, 3302-3311, 2005.

Schreiner, J., Voigt, C., Kohlmann, A., Arnold, F., Mauersberger, K., and Larsen, N.: Chemical analysis of polar stratospheric cloud particles, Science, 283, 968-970, 1999.

Solomon, S.: Stratospheric Ozone Depletion: A Review of Concepts and History, Rev. Geophys., 37, 275-315, 1999.

Spang, R., Riese, M., Eidmann, G., Offermann, D., and Wang, P. H.: A detection method for cirrus clouds using CRISTA 1 and 2 measurements, Adv. Space Res., 27, 1629-1634, 2001.

Spang, R., Riese, M., and Offermann, D.: CRISTA-2 observations of the south polar vortex in winter 1997: A new dataset for polar 
process studies, Geophys. Res. Lett., 28, 3159-3162, 2001.

Spang, R., Eidmann, G., Riese, M., Offermann, D., Preusse, P., Pfister, L., and Wang, P.-H.: CRISTA observations of cirrus clouds around the tropopause, J. Geophys. Res., 107(D23), 8174, doi:10.1029/2001JD000698, 2002.

Spang, R. and Remedios, J. J.: Observations of a distinctive infrared spectral feature in the atmospheric spectra of polar stratopsheric clouds measured by the CRISTA instrument, Geophys. Res. Lett., 30, 2003.

Spang, R., Remedios, J. J., and Barkley, M. P.: Colour indices for the detection and differentiation of cloud types in infra-red limb emission spectra, Adv. Space Res., 33, 1041-1047, 2004.

Spang, R., Remedios, J. J., Kramer, L. J., Poole, L. R., Fromm, M. D., Müller, M., Baumgarten, G., and Konopka, P.: Polar stratospheric cloud observations by MIPAS on ENVISAT: detection method, validation and analysis of the northern hemisphere winter 2002/2003, Atmos. Chem. Phys., 5, 679-692, 2005.

Steck, T.: Methods for determining regularization for atmospheric retrieval problems, Appl. Opt., 41, 1788-1797, 2002.

Strawa, A. W., Drdla, K., Fromm, M., Pueschel, R. F., Hoppel, K. W., Browell, E. V., Hamill, P., and Dempsey, D. P.: Discriminating Types Ia and Ib polar stratospheric clouds in POAM satellite data, J. Geophys. Res.,107(D20), SOL 34-1, 8291, doi:10.1029/2001JD000458, 2002.

Tabazadeh, A., P.Turco, R., Dradla, K., Jacobson, M. Z., and Toon, O. B.: A study of type I polar stratospheric cloud formation, Geophys. Res. Lett., 21, 1619-1622, 1994.

Tabazadeh, A., Jensen, E. J., Toon, O. B., Drdla, K., and Schoeberl, M. R.: Role of the stratospheric polar freezing belt in denitrification, Science, 291, 2591-2594, 2001.

Tisdale, R. T., Prenni, A. J., Iraci, L. T., Tolbert, M. A., and Toon, O. B.: Variation of the infrared spectra of nitric acid hydrates with formation conditions: Impact on PSC identification, Geophys. Res. Lett., 26, 707-710, 1999.

Toon, G. C., Farmer, C. B., Lowes, L. L., Schaper. P. W., Blavier, J.-F., and Norton, R. H.: Infrared aircraft measurements of stratospheric composition over Antarctica during September 1987, J. Geophys. Res., 94, 16,571-16,596, 1989.

Tizek, H., Knözinger, E., and Grothe, H.: X-ray diffraction studies on nitric acid dihydrate, Phys. Chem. Chem. Phys., 4, 51285134, 2002.

Tizek, H., Knözinger, E., and Grothe, H.: Formation and phase distribution of nitric acid hydrates in the mole fraction range $\mathrm{x}_{\mathrm{HNO}_{3}}<0.25$ : A combined XRD and IR study, Phys. Chem. Chem. Phys., 6, 972-979, 2004.

Tolbert, M. A. and Toon, O. B.: Solving the PSC Mystery, Science, 292, 61-63, 2001.

Toon, O. B. and Tolbert, M. A.: Spectroscopic evidence against nitric acid trihydrate in polar stratospheric clouds, Nature, 375, 218-221, 1995.
Toon, O. B., Browell, E. V., Kinne, S., and Jordan, J.: An analysis of lidar observations of polar stratospheric clouds, Geophys. Res. Lett., 17, 393-396, 1990.

Toon, O. B., Tolbert, M. A., Middlebrook, A. M., and Jordan, J.: Infrared optical constants of $\mathrm{H}_{2} \mathrm{O}$, ice, amorphous nitric acid solutions, and nitric acid hydrates, J. Geophys. Res., 99, 25631 $25654,1994$.

Vanhellemont, F. , Fussen, D., Bingen, C., Kyrölä, E., Tamminen, J., Sofieva, V., Hassinen, S., Verronen, P., Seppälä, A., Bertaux, J. L., Hauchecorne, A., Dalaudier, F., Fanton d'Andon, O., Barrot, G., Mangin, A., Theodore, B., Guirlet, M., Renard, J. B., Fraisse, R., Snoeij, P., Koopman, R., and Saavedra, L.: A 2003 stratospheric aerosol extinction and PSC climatology from GOMOS measurements on Envisat, Atmos. Chem. Phys., 5, 2413-2417, 2005.

Voigt, C., Schreiner, J., Kohlmann, A., Zink, P., Mauersberger, K., Larsen, N., Deshler, T., Kröger, C., Rosen, J., Adriani, A., Cairo, F., Di Donfrancesco, G., Viterbini, M., Ovarlez, J., Ovarlez, H., David, C., and Dörnbrack, A.: Nitric Acid Trihydrate (NAT) in Polar Stratospheric Clouds, Science, 290, 1756-1758, 2000.

von Clarmann, T., Glatthor, N., Grabowski, U., Höpfner, M., Kellmann, S., Kiefer, M., Linden, A., Mengistu Tsidu, G., Milz, M., Steck, T., Stiller, G. P., Wang, D. Y., Fischer, H., Funke, B., GilLópez, S., and López-Puertas, M.: Retrieval of temperature and tangent altitude pointing from limb emission spectra recorded from space by the Michelson Interferometer for Passive Atmospheric Sounding (MIPAS), J. Geophys. Res., 108(D23), 4736, doi:10.1029/2003JD003602, 2003.

von Savigny, C. , Ulasi, E. P., Eichmann, K. -U., Bovensmann, H., and Burrows, J. P.: Detection and mapping of polar stratospheric clouds using limb scattering observations, Atmos. Chem. Phys., 5, 3071-3079, 2005.

Wagner, R., Mangold, A., Möhler, O., Saathoff, H., Schnaiter, M., and Schurath, U.: A quantitative test of infrared optical constants for supercooled sulphuric and nitric acid droplet aerosols, Atmos. Chem. Phys., 3, 1147-1164, 2003.

Wagner, R., Möhler, O., Saathoff, H., Stetzer, O., and Schurath, U.: Infrared Spectrum of Nitric Acid Dihydrate: Influence of Particle Shape, J. Phys. Chem. A, 109, 2572-2581, 2005.

Worsnop, D. R., Fox, L. E., Zahniser, M. S., and Wofsy, S. C.: Vapor pressure of solid hydrates of nitric acid: implications for polar stratospheric clouds, Science, 259, 71-74, 1993.

Zhang, R., Wooldridge, P. J., and Molina, M. J.: Vapor pressure measurement for the $\mathrm{H}_{2} \mathrm{SO}_{4} / \mathrm{HNO}_{3} / \mathrm{H}_{2} \mathrm{O}$ and $\mathrm{H}_{2} \mathrm{SO}_{4} / \mathrm{HCl} / \mathrm{H}_{2} \mathrm{O}$ systems: Incorporation of stratospheric acids into background sulfate aerosols, J. Phys. Chem., 97, 8541-8548, 1993. 